\title{
EXISTENCE AS RESISTANCE IN TKARONTO: IDENTITY FORMATION FOR LATINX LGBTQ PEOPLE
}

By

\author{
Martha Segovia, Bachelor of Social Work, 2016, York University, Toronto, Ontario, Canada \\ An MRP \\ presented to Ryerson University \\ in partial fulfillment of the \\ requirements for the degree of \\ Master of Social Work \\ in the Program of \\ Social Work
}

Toronto, Ontario, Canada, 2019

(C) Martha Segovia 2019 


\section{AUTHOR'S DECLARATION FOR ELECTRONIC SUBMISSION OF A MRP}

I hereby declare that I am the sole author of this MRP. This is a true copy of the MRP, including any required final revisions.

I authorize Ryerson University to lend this MRP to other institutions or individuals for the

$$
\text { purpose of scholarly research }
$$

I further authorize Ryerson University to reproduce this MRP by photocopying or by other means, in total or in part, at the request of other institutions or individuals for the purpose of scholarly research.

I understand that my MRP may be made electronically available to the public. 
About the Author

I am a Salvadoran-born, first generation Latinx settler-accomplice in Canada. My practice as well as my emergent social work scholarship is informed from an inherently intersectional position. Based on my lived experience as a former newcomer to Canada and as a queer Person of Colour, I aim to build rapport and trusting relationships in my capacity to support others having similar experiences to my own. I have experience working with underrepresented communities like newcomers to Canada, 2SLGBTQ youth, and seniors where I find advocacy work to be second nature in capacity. Additionally, during the completion of my Social Service Worker diploma at Seneca College, I acquired community-based research experience working alongside children, youth, and families in the Rexdale neighbourhood. As a Bachelor of Social Work fellow at York University, I worked with youth, undergraduate students, and Social Work professors for community-building in the New Opportunities for Innovative Student Engagement (NOISE) program. I look to utilize an intersectional framework born from my own intersections for the advancement of diverse populations and possibilities for engagement. 


\begin{abstract}
Existence as Resistance in Tkaronto: Identity Formation for Latinx LGBTQ People

Martha Segovia

Master of Social Work, 2019

Ryerson University
\end{abstract}

Latinx proposes to intersect the space in-between identities. An intersectional framework engaged in a quantitative process is utilized to demonstrate the identity formation for Latinx 2SLGBTQ people living in the City of Toronto. Through looking at the work of Latinx authors developing the testimonios scholarship, various themes emerged from the authentic and multifaceted existences of the research participants. Four themes consisting of various multidimensional factors articulate the participant's experiences as Othered and Latinx 2SLGBTQ people. Recording and transcribing three narratives from Latin American-identifying 2SLGBTQ people in their lived experience in Toronto suggests the need for a call for inclusive change in the Latinx and 2SLGBTQ communities. 


\section{Acknowledgement}

I dedicate this effort to the queer and trans Latinx rebels coming before me, those in the margins to those paving a drive to resistir. I dedicate this to those resisting the present colonial margins denying positions in settler colonialism which continue to erase the 2SLGBTQ Latinx existence.

I dedicate this effort to my family in El Salvador. To my biggest inspirations, my brother and mother, thank you for loving me as I am. To my chosen friends and family, thank you for inspiring me. To those living and resisting everyday, I see you. 
Table of Contents:

Page

Author's Declaration

II

About the Author

III

Abstract

IV

Acknowledgement

V

Chapter 1: Introduction

01

Chapter 2: Literature Review

07

Chapter 3: Theoretical Frameworks

18

Chapter 4: Methodology

24

Chapter 5: Findings

31

Chapter 6: Discussion

42

Chapter 7: Conclusion

Appendices

49

References

63 
List of Appendices:

Page

Appendix A - Recruitment Poster 49

Appendix B - Facebook Post 50

Appendix C - Consent to Participate Form 51

Appendix D - Demographic Form 56

Appendix E - Interview Guide $\quad 58$

Appendix F - Counselling Support Services for Participants 61 


\section{INTRODUCTION: CHAPTER 1}

In this Major Research Paper (MRP), the term Latinx refers to those identifying as Latin American and as members of the two-spirit, lesbian, gay, bisexual, transgender, and queer (2SLGBTQ) community living in Toronto, Canada. As a Latinx and queer person, this research is profoundly personal as a narrative of resistance that draws on ancestral teachings as a Salvadoran migrant in accordance with living as an uninvited settler on Mississaugas of New Credit land in Tkaronto. 'Latinx' as an identity construct emerges from scholarship, online spaces and as a placeholder to assert resiliency. Latinx has built a place for discussing Latin American landscapes inclusive of gender non-conforming and two-spirit, lesbian, gay, bisexual, transgender and queer (2SLGBTQ) identities. The multidirectional and multidimensional realities of surviving the trappings of the acronym reimagine a self full of infinite possibilities of how our black, brown and olive coloured bodies construct our gender identity, gender expression, sexualities and attractions over the course of the lifetime.

The condensed one-year duration of the Master of Social Work Program at Ryerson University required focused research. Support and discussion from a Two-Spirit Indigenous Knowledge Keeper assisted in the recommendation for a narrowed research focus examining the population to which I belong. Indigenous 2SLGBTQ persons duly experience a heightened degree of hardship from an ongoing colonial legacy through nefarious processes to disqualify Indigenous identities. Additionally, the complex lived experience of Black 2SLGBTQ persons who continue to fight for Black Liberation presents a space for personal reflection for engagement in Anti-Indigenous Racism and Anti-Black Racism pedagogy. In the end, I reflected

deeply on my initial research question which resulted in a research question which solely focused on the Latinx community in the City of Toronto. At the same time, however, thinking through 
reflexive action and a commitment to intersectionality and decolonial engagement has led to research which is inclusive of thought from Indigenous and Black authors. Ladson-Billings (2003) describes the need for diverse scholarship by diverse voices to decentre traditional research, "It is to challenge the hegemonic structures (and symbols) that keep injustice and inequity in place" (p. 271)

Critical Race and queer Theorist Sara Ahmed discussed "Queer Use" as a taking up of a term entrenched in history hurled against queer and trans existences to one of reclaiming identities (Cam, 2019). "Queer” has historically been weaponized in its use against unheard, undervalued communities as a procedure in the Othering process where it has proven to be a double-edged sword in that the different and Othered re-claim queer in the community namesake and in referencing diverse embodiment of gender and sexual orientation. Queer has become an identity formed from ongoing resistance. The Othering process designates and categorizes social groups defining the minority including women, racialized, and sexually diverse groups (KrumerNevo, 2002). In the sphere of the Other, Krumer-Nevo (2002) examines the differentiation between the "we" and the "them" wherein "them" constitutes the hegemonic and colonial subjectivity of the white, heteronormative being.

As a Salvadoran-Canadian and queer Latinx person, meanings of identity surround a growing understanding of the self in relation to a multi-directional informed identity. As an immigrant from the Central American isthmus, discussions about the Latin American experience signify a personal commitment to examine such identity through its nuances. As the late Chicana $^{1}$ author and self-identified Lesbian, Gloria E. Anzaldúa (1987) proposes in her

\footnotetext{
${ }^{1}$ Gloria Anzaldúa's contribution to the emergence of Chicana cultural studies cannot be understated. Through her multi-informed experiences, she contributed to examining the conditions of Latina and Chicana identities among others
} 
Borderlands Theory - one's locale encompasses the multi-informed positioning of the self through the social, the self through the political, and the self through the land, where such notions inform the position of the new Mestiza. In acknowledging my own Mestiza formation from a mixed heritage noting a historical colonial rule in El Salvador and a present settlerhood on Indigenous land, I look to subscribe to decolonial engagement from the innate understanding of the self towards external action. Existing in a Brown woman's body through the Mestizaje of an Indigenous and colonial existence, I have come to understand numerous discursive formations of labeling through the external gaze. Identities and terms such as "Latina", "Spanish", and "Hispanic" have been attached to my body. At various points over the course of my life, I have come to self-identify with such terms qualifying perceptions of who I am. I note my brown skin presumably offers outsiders an invitation to assign labels and boxes upon my body to fit a discourse which inevitably excludes similar voices. As such, identity formation has been an evergrowing journey, one that provides challenges through processes of self-development. It has been experiences of migration, assimilation, and re-imagination as a first-generation, Salvadoran-Canadian which provide the context and opportunity to explore the self as a migrant subjected to colonial rule within the Canadian context of multiculturalism. I parallel such examinations of the self as a settler accomplice with Indigenous heritage from the Pipil people of El Salvador. Negotiating a Pipil and Latinx identity allows me to consider where I exist in a personal representation of the physical and non-physical realms of the borderlands as an instrument for the attainment of decolonization.

We can understand the Latin American identity through diverse factors encompassing schisms of geography, governance, and factors of gender, sexuality, and the like. As state governance erects physical borders in North and Central America most notably along the United 
States and Mexico border which has obstructed asylum, such governmental processes for oppression parallel the experiences of Latin American 2SLGBTQ people as migrants or individuals seeking a home. Such discussions contribute to Latinx studies through baring one's testimonios (testimonies). Testimonios as a narrative methodological process focus on stories as told by the narrator (Reyes \& Curry Rodriguez, 2012). They function to name oppressive factors of the research process through renewed acts of reflection and autonomy (Reyes \& Curry Rodriguez, 2012.)

Latinx 2SLGBTQ persons face complex intersections in their existence as racially diverse, multi-ethnic, and multi-cultural beings among procedures of migration, citizenship, and linguistic abilities (Dueñas, Adames, Perez-Chavez, Salas, Chavez-Dueñas, Adames, Salas, 2019). Latinx persons carry a heavy weight as persecuted beings due to their diverse gender and sexual orientation in their homelands and remotely in countries of migration such as those behind inhumane cages and walls which encroach on their livelihood (Board, 2019; Dueñas et al., 2019; Doetsch-Kidder \& Bracamonte, 2011; Ramírez, 2006). Narrative interviews focusing on the participants' testimonios will base examinations embarking on an identity formation journey from the comunidad. Community formations inspire the direction for inclusive frameworks and epistemologies from Indigenous, Black, and Brown scholars to inform such communal pursuits for discussing the research at hand.

Intersectional frameworks including Critical Race Theory, Latino Critical Theory, and Queer Theory allow an understanding of the Latinx identity beyond social constructions of race and gender. In the testimonial discussions, the interview produces a decolonizing method. Bagele Chilisa (2012) offers that, "A postcolonial Indigenous research paradigm offers other possible interview methods which privilege relational ways of knowing that valorize respect for relations 
people have with one another and with the environment" (p. 206). Bagele Chilisa's line of thought serves to acknowledge ancestral notions of Indigenous methodology in the research processes. Exploring confluence that is not about locating friction, but opportunities of ways forward is located through Indigenous ways of knowing and Western research methods, is a process known as Two-Eyed Seeing. This approach, introduced to this writer by Secwepemc scholar Jeffrey McNeil-Seymour, encompasses dual frameworks of Indigenous and Western thought. I look to engage a harmonious place of Two-Eyed Seeing utilizing appropriate Indigenous and Western epistemologies. Any such spaces provide opportunities for learning and engagement while observing the land, its occupants, and the universe (Knapp, 2013).

Latinx storytelling is a grounding methodology used in the research. Latinx scholarship builds a growing space among academic spheres allowing for narratives inclusive of their testimonios. As Latinx identities can encompass multiple ethnicities and a multitude of nuances in rejection of the mainstream, it is pertinent to include examinations of underrepresented voices such as those of people of Indigenous and Afro-Latinx heritage. Through reflexive engagement, three participants discuss what defines them through the complexities of identity formation. What is identity formation for Latinx 2SLGBTQ individuals in the City of Toronto? It is the time and place of the borderlands, the in between, and living among the fringes that characterizes a Latinx identity in Toronto. It is the processes of queering the borderlands over the flowing waters of the Humber River in the West to the Don River of East of the City connecting to the Huron named Lake Ontario, which rejects heteronormativity and allows us to invite, honour, and write the stories of our multiple experiences (Pérez, 2003). Examining one's own engagement with a settler colonial state and navigating connection with distant native lands informs the discussions noting how entrenched identities become. Discussions based on the ethno-racial, gender and 
sexually diverse experiences of participants informs the physiological place for creation of transformative and decolonial processes for identity formation. 


\section{LITERATURE REVIEW: CHAPTER 2}

Indigenous, Black, and People of Colour face processes of exclusion throughout their existence. Latinx, as a non-homogeneous group, exists among complex intersections. The geographical composition of intersections can affect the self throughout Latin American migrant communities to English-dominant countries such as the United States and Canada. Within systems of oppression, the Othering process exists to outline reactive measures to diverse bodies outside the dominant existence (Dueñas et al., 2019). Dueñas et al. (2019) posit that such processes inform the impacts in the form of discrimination faced by Latinx immigrants in the United States and Canada. It is in such Western states where individuals face multi-layered and diverse influences of prejudice and discrimination as an Othered population (Dueñas et al., 2019).

\section{Local Findings on Racialized 2SLGBTQ Populations}

Whiteness as a Eurocentric and colonial product promotes and generates directives of exclusion in white-centred LGBTQ spaces. Within local spaces, Logie \& Rwigema (2014) observe whiteness as lesbian, bisexual, and gay (LBG) women report instances of white privilege as a discourse informing the non-representation of racialized women in such spaces. Participants express their experiences of discrimination beyond an individual's sexual orientation as they face a myriad of cross-woven experiences of exclusion concerning their gender identity, class, and race (Logie \& Rwigema, 2014). Service provision in LGBTQ spaces exemplifies the process of discrimination by centralizing white settler colonial attitudes and heteronormative societal confines (Gamarel, Walker, Rivera \& Golub, 2014; Giwa \& Greensmith, 2012; Greensmith, 2015, Logie, \& Rwigema, 2014; Whitfield, Langenderfer-Magruder \& Clark, 2014). These articles suggest that the Othering process is categorically experienced by those existing outside 
white settlerhood. Laterally among LGBTQ communities, the Othering process is prevalent which emboldens Anti-Indigenous sentiment and further advances the production of the modern colonial project in queer service provision (Greensmith, 2015). Thus, whiteness and its exclusionary racial exploits are inherent in the very fabric that constructs LGBTQ spaces in Toronto (Giwa \& Greensmith, 2012). In examining narratives of Latinx 2SLGBTQ persons in Toronto, questions of existing within white settler spaces inform an individual's positionality. This research will examine experiences as bodies subjected to colonial forces in Latin American history, and Latin American as an identity encompassing wide-ranging categories not limited to multi-ethnic, multi-generational, cultural, and racial demographics including lineage to from the Indigenous peoples of the Americas (Ramírez, 2006).

\section{Latinx People in the Diaspora of the Americas}

Madelaine Cristina Cahuas (2018) examines the growing Latin American migratory population in the Greater Toronto Area (GTA) from the 1960s onward. Latin American history saw surges in settlement process in various decades due to ranging socioeconomic conditions affecting the Latin American diaspora such as dictatorships and civil wars (Cahuas, 2018). In a focused examination of Central American LGBTQ people, Medecins Sans Frontieres (2017) notes that LGBTQ persons experience exacerbated risk during migration. Experiencing discrimination in their countries of origins, LGBTQ individuals often seek refuge abroad. LGBTQ Central Americans experience state violence and societal exclusion (Medecins Sans Frontieres, 2017) and look to flee violent strongholds affecting their right to live, sometimes looking to the north for refuge. As history shows, Latin Americans throughout the world are subject to loss in numerous forms such as land loss and discriminatory practices which result in a necessity to survive and, even occupy, through migration processes (Pérez, 2003). Dueñas et al., 
(2019) explore ethno-racial trauma affecting Latinx immigrants in the United States. The researchers determine that collective mental duress and violence in various forms exist as factors affecting the community on individual and group levels. Latin Americans endure compounding effects of varied exposure. Scholars have considered an ethno-racial trauma theory that examines the mosaic composition of Latin Americans (Dueñas et al., 2019).

Horacio N. Roque Ramírez (2006) produces teaching strategies for students to understand the LGBT Latino/a American experience in the United States. Through the borderlands, the diaspora, and the "transnation", he notes the individual and collective struggles of Latino/a Americans as multi-racial, multi-lingual, multi-national identities much like his own struggles as a gay Salvadoran-American scholar. In literary contributions, Chicana authors Gloria E. Anzaldúa and Cherrie L. Moraga speak of the queer, Latino experience as originating from the borderlands of existence. Ramírez (2006) defines this idea of the borderlands as, "A site for political, historical, and sexual consciousness for appreciating the coming together of different cultures" (p. 40). On the individual and community level, such impacts are not unilateral where intersections of various conditions play a determining factor on the individual Latinx person. Dueñas et al., (2019) posit that oppositional actions informed by racist ideology, xenophobia, and heteronormative attitudes through a capitalist lens inform certain experiences endured by Latin Americans. In the individual realm, such attitudes may present externally through discriminatory practices towards Latin Americans as racial minorities living in the North American diaspora to the employment of anti-immigrant policies and sentiments by states-atlarge (Dueñas et al., 2019) 
Heteronormative attitudes or machismo all inform the historical condition of the Latin American identity largely impacting the female or 2SLGBTQ Other (Mayo and Resnick, 1996). Scholars regard such impacts on gender diverse or non-heterosexual Latinx people as being taxing to one's existence (Cahuas, 2018, Jiménez, 2008; Mayo and Resnick, 1996). As colonial discourse affects society's conditions, machismo and its binary framing of gender identities impacts large and small social systems including the immediate family. For example, Ed Chamberlain (2018) examines the testimonios of queer Latin Americans as compiled from various collections which highlight processes of prejudice against queer identities. In the Latin American familial structure such external conditions impact the individual through a discourse aligning with heteronormative conditions. Chamberlain (2018) examines a mother and daughter testimonio where the narrative exemplifies a strife-ridden relationship stemming from a heteronormative standard creating friction within the bond. A mother's subscription to heteronormative rules indicates a narrative marking the queer body as shameful and immoral meanwhile, presenting a complex space of confrontation. Chamberlain (2018) examines the conflicting societal space in the possibility of embracing non-heterosexual identities as, "The notion of "overflow" where such realms means a queer characterization prompted by the desires of LGBTQ people as perceived by straight people as sprawling beyond the realm of the socially acceptable" (p. 266). Anzaldúa (1987) defines culture as informing our beliefs, she notes: "Dominant paradigm, predefined concepts that exist as unquestionable, unchallengeable, are transmitted to us through culture" (p. 38). Who are those authors writing the leading concepts? Anzaldúa (1987) identifies those in power - men, as the dominant gender class. Anzaldúa (1987) further describes the production of a male-oriented culture informing a tribe's welfare including dismissing deviant behaviour. Discourse informing the socially acceptable and common 
behaviour attempts to dissipate the gender and sexually diverse Other, "The queer are the mirror reflecting the heterosexual tribe's fear: being different, being other and therefore, lesser, therefore sub-human, in-human, non-human (Anzaldúa, 1987, p. 40).

In collecting experiences of Latinx folk through the Social Justice Sexuality (SJS) project, the survey presents a substantive tool to examine the expansive factors affecting Latin Americans in the United States (Pastrana, Jr., Battle \& Harris, 2017). Data examines the nuanced narratives of Latinx 2SLGBTQ people and their identities through a series of questions prompting an examination of personal perspectives and their cultural identity formation (Pastrana, Jr. et al., 2017). Given the patriarchal and heteronormative historical formation of the Latin American familial ideal, 45\% of the Latinx LGBT SJS Survey respondents note being "out" to all in their families with $38 \%$ of such respondents disclosing feeling fully, "completely supported by their families" (Pastrana, Jr. et al., 2017, p. 38 \& p. 53). These findings support the need for extensive discussions exploring the Latinx self and the North American diaspora.

As North and Central America comprise the geographical confines which emerge as colonial and imperialist lands encroaching on such Latinx bodies, the need to examine discourse surrounding land pedagogy is warranted for a decolonial approach rejecting such imperialist attitudes. In decolonial methodology beyond quantitative measures, researchers can include the narratives and testimonios of Latinx individuals to reject a colonial threshold comprising diverse identities. It is through intersectional engagement acknowledging the nuances of Latinx identities where research can reflect the multiple forms of discrimination and oppression within the systems arranged on the diverse Latinx bodies (Pastrana, Jr. et al., 2017). In the considerations of the diaspora and the borderlands, the Latinx identity prevails, among such social structures embedded from a colonial hegemonic empire which ascribe to reject indifference. 


\section{Indigenous, Black and Latinx People in their Social Engagement}

Latin Americans, like other ethnic or racialized groups, exist in society through complicated and enwoven threads which determine an ability to pursue engagement even within spaces aligned as "safe" such as those marked as 2SLGBTQ-friendly spaces (Bailey, 2014; Giwa \& Greensmith, 2012; Greensmith, 2015, Greensmith, 2018, Logie \& Rwigema, 2014). Within LGBTQ communities, exclusion is rampant in the form of racism entrenched within, and homophobia present among racialized communities (Bailey, 2014; Whitfield et al., 2014). In scholarly examinations, LGBTQ spaces promoted as inclusionary are marred by prejudice based on white-centred notions carried forth by colonialism, cis-normative or heteronormative representations (Giwa \& Greensmith, 2012; Greensmith, 2015, Greensmith, 2018). Racialized LGBTQ individuals experience critical rates of discrimination and disenfranchisement in various environments (Bailey, 2014; Gamarel et al., 2014; Giwa \& Greensmith, 2012; Hudson \& Mehrotra, 2015; Whitfield et al., 2014; de Vries, 2015). Certain marked bodies on the 2SLGBTQ spectrum face greater threats such as transgender women of colour as anti-transgender sentiments explicitly prevail (Human Rights Campaign, n.d.; Wheeler, Anfinson, Valvert \& Lungo, 2014). According to the Human Rights Coalition, the United States saw 26 violent homicides of trans individuals, mostly transgender women of colour, in 2018 (Human Rights Campaign, n.d.). Transwomen of colour experience higher rates of HIV-positive statuses from their engagement in multiple partner sexual engagement as an underlying need for survival further exacerbating the critical prevalence of substance use and sexually transmitted infections (Sausa, Keatley \& Operario, 2007). For LGBTQ Central Americans results show men who engage in sex with men (MSM) and transgender women are at a disadvantage in negotiating safer sex practices, increasing susceptibility to HIV/AIDS, STIs, and compounding challenges to 
accessing appropriate health services (Wheeler et al., 2014). Within countries of origin and in North American spaces, Latinx individuals further experience health detriments due to discrimination in the health system and in accessing social spaces (Dueñas et al., 2019; Mayo \& Resnick, 1996). Nonetheless, Latinx 2SLGBTQ individuals perceive their general health, including mental health, existing in similar regards to other People of Colour (Pastrana, Jr. et al., 2017). In addition, Pastrana, Jr. et al., (2017) report Latinx individuals feel equally connected to the racialized 2SLGBTQ community thus bridging a parallel to other 2SLGBTQ People of Colour in factors of health and well-being.

Bailey (2014) examines the ballroom scene, where Black and Brown LGBTQ individuals congregate to create a social space for their existence. Bailey (2014) notes such individuals seek out transformative reigns to create space to exist: "For Ballroom members, space is cultural production rather than a concretized fixed location" (p. 490). The interconnectedness of gender and sexuality variance grandly affect a person's access to survive as their authentic self within social spaces. Bailey (2014) notes that the biological family often denounces the nonheteronormative person, thus the need for creation of space where the excluded thrive: "Reconstitute a heteronormative homeplace into a queer house, one that welcomes and nurtures their Black LGBT lives" (p. 498). As ordinary venues transform through the spatial practice of the ballroom, Black queer people carve inclusive and communal space (Bailey, 2014). The inclusion of physical and physiological place allows the processes of identity formation. Beyond the physical and physiological place of existence, Black and Latinx Americans present ethnoracial considerations of diverse identities in their diverse consideration of same-sex marriage (Harrison \& Michelson, 2017). Four research experiments note non-monolithic attitudes from Black and Latinx respondents, reflecting dynamic social conditions and racial bias among such 
groups (Harrison \& Michelson, 2017). Harrison and Michelson (2017) further report an ethnoracial identity prevails in social conditions for the racialized Other as Latino/a Americans express a substantive and loyal connection to the Latin group or a national ethnic group of origin. Latino/a Americans were found to be open to supporting same-sex marriage, however, through a conditional regard depending on factors pertaining to citizenship, migration, and linguistic circumstances of the study methodologies. Race-of-interviewer effects illustrate a conflicting response depending on the interviewer's race and identity (Harrison \& Michelson, 2017). For example, a Black or Latino/a respondent supported same-sex marriage if reached out to by a fellow member of that group (Harrison \& Michelson, 2017). Harrison \& Michelson (2017) state that respondents were not intentionally made of aware of the interviewer's race or ethnicity however respondents were able to clue in on the identities of the project staff. As Latinx identities expand racial and ethnic lines, additional research experiments present the diverse conditions of 2SLGBTQ identities in their development through such social factors and conditions.

LGBTQ Spanish-speaking people were surveyed on the positive aspects of their identity (Almario, Riggle, Rostosky \& Alcalde, 2012). A Colombian participant spoke of the pride in self-advocacy and the sharing of pertinent legal information with younger populations (Almario et al., 2012). Acknowledging the negative societal outcomes ascribed to LGBTQ persons, the study showed positive aspects of identity formation, space creation, and survival (Almario et al., 2012). The survey of Spanish-speaking LGBTQ persons noted that, "Positive experiences of self-identity contribute to a sense of well-being, optimal human functioning, and flourishing" (Almario et al., 2012, p. 7). Within examining identity formation, intersectional aspects of existence are weighed differently according to the individual and their circumstances. As de 
Vries (2015) notes, through producing a multidimensional model of twelve categories existing in the experiences of transgender persons of colour, racialized transgender identities produce complex identity discourse beyond gender and sexuality. Within trans identities, the manifestation of inequality and discrimination exists in varied form in part due to such diverse bodies. Nonetheless, trans persons do not experience gender removed from other social categories of sexuality, class or race (de Vries, 2015). In gathering literature and analysis, one can note further examination and analysis is of importance to support racialized transgender and gender non-conforming individuals.

Latinx people have a thriving vigour, a resilience born from ancestral roots and, as such, Latino/a Americans have a history in activism. As non-homogenous groups, Latinx people have fought battles forged by oppressive regimes and their production from governmental forces to non-governmental forces eradicating possibilities of transformative engagements. In one example, on June $19^{\text {th }}, 1997$, in the heart of San Salvador, El Salvador, various groups led by queer ex-guerilla female fighters rose from seclusion to publicly display their diverse identities in the country's first Pride Parade. Through such a display, the parade signified a start in radical group formation for advancement of the small nascent LGBTQ population in the conservative country of El Salvador (Courtright, 2016).

Notwithstanding, recent developments have exemplified the fatal directives of prejudice against 2SLGBTQ individuals in the Americas. Black and Brown LGBTQ individuals were the target in a 2016 "Latin Night" event at Pulse Night Club in Orlando, Florida, as 49 patrons were killed, largely those of a Latinx identity (Kline \& Cuevas, 2018). In creation of Latinx space, community activism for and by diverse Latinx identities has rooted a collaborative environment for authentic storytelling, healing, and community activation (Torrez, Gonzales, del Hierro, 
Ramos \& Cuevas, 2019). As responses to the Pulse Night Club tragedy, communities in the Orlando area forged active groups to combat anti-immigrant and anti-LGBTQ sentiments among lacklustre response from conservative politicians (Kline \& Cuevas, 2018). In a response to the concerning environment breeding white supremacist ideology, 'QLatinx', a Latinx organization, was formed for an intersectional approach to govern the community needs through social engagements. Kline and Cuevas (2018) stated this as, "Local political mobilization directly informed by intersectional experiences" (p. 70). In Orlando, Florida, such responses allowed for formation of creative, healing space during hardship.

\section{Rewriting Latinx Narratives}

Narratives grow from a need to create space, especially for voices that have been historically silenced. It is mediums of the politic, community, and the individual that inform transformative possibilities. Critical race theories and feminist notions of the personal is political inform intersectional and decolonial engagement (Crenshaw, 1991). Narratives which parallel the engagement of Latinx, and Indigenous identities create informative and decolonial space. The "Nuestros Cuentos" (Our Stories) program taking place on Nkwejong, an Anishinaabemowin space with the colonial names of Lansing and East Lansing, Michigan, has allowed young Latinx persons to construct their narratives through storytelling and art-based medium formats (Torrez et al., 2019). As Torrez et al., (2019) note, the project has informed a space for Latinx and Indigenous middle-schoolers to generate personal narratives through intermediary supports by educators and post-secondary mentors. The "Nuestros Cuentos" program exemplifies decolonizing practices within formal educative spaces that return to an ancestral pedagogy (Torrez et al., 2019). As Chilisa (2012) notes, reciprocity and relationality are factors determining an Indigenous pedagogy. As reciprocal and relational processes produce a 
decolonial engagement, it is programs like the "Nuestros Cuentos" which serve to celebrate a connection with land pedagogy and the intersectionality of diverse people (Torrez et al., 2019).

Cahuas (2018) similarly examines the experiences of Latinx Community Workers within a monolithic non-profit structure as a group embedded in a neoliberal and patriarchal political system allowing for historical systems of male-dominated leadership to thrive. Monolithic colonial and patriarchal systems existing under neoliberalism are found in North American politics as they are in Latin American politics infringing on community-led diversity processes of engagement and development. Cahuas (2018) further notes such community workers existing dually in the non-profit sector as workers and members encounter oppressive regimes based on gender in the Latin American community and society at large.

It is through transformative possibilities acknowledging multi-versed identities where the Latinx community can build spaces informed by Indigenous pedagogies, Latin American cultural foundations, and anti-monolithic approaches. As Estrada (2003) imagines an Aztec and Two Spirit cosmic reverence of the masculine and feminine in sunrise and sunset, the 2SLGBTQ Latinx identities inform one's individual desire for harmonious existence among chaos: "In both cases, energy only exists in relation to other energies, and one kind can transform into another, just as matter can transform into energy and back if given the right time and place" (p. 12). Thus, gathering foundations from various systems allows for examination of the Latinx identity to move from a familiar viewpoint to one of new engagement. 


\section{THEORETICAL FRAMEWORK: CHAPTER 3}

Kimberle Crenshaw (1991) theorizes intersectionality to contextualize the lived experiences of Black Women, and other racialized women through the dimensions of sex and gender. Crenshaw (1991) notes identity politics fail in noting the varied experiences of individuals. She contends that identity politics undermine one's intersections, arguing that, "Ignoring difference within groups contributes to tension among groups, another problem of identity politics that bears on efforts to politicize against women" (Crenshaw, 1991, p. 1242). Crenshaw (1991) postulates that identity politics aim to separate opposing group identifiers as they go unchallenged by the leading class which define exclusionary civil movements. Colonial methods of race and race privilege allow constitutional processes to define and control Othered bodies whereas Critical Race Theory and Latino Critical Theory (LatCrit) introduce counter measures to such markers of race and ethnicity. Critical Race Theory and Latino Critical Theory engage the manifestation of oppressive factors through processes of race and ethnicity as Queer Theory engages sexuality (Bernal, 2002; Daftary, 2018; Ladson-Billings, 2003). Queer Theory deconstructs categories of gender and sex, sexual orientation, and identity performance.

\section{Language}

The use of 2SLGBTQ and LGBTQ acronyms are intentional in producing discussions critiquing settler colonial practices in such communities. Given the primary acronym in this presentation includes Two-Spirit as an Indigenous identity, when discussing colonial, whitecentred spaces, and service provision I will note the LGBTQ acronym. Robinson (2017) describes Two-Spirit in contemporary time as a diverse sexual and/ or gender identity, one that is distinct among Indigenous and First Nations communities and cultures. Two-Spirit people hold sacredness among their communities holding positions of leadership and role assignment 
(Robinson, 2017). The acronym 2SLGBTQ encompasses some identities under the umbrella and rainbow spectrum of diverse sexual orientations and gender identities. Save for the $2 \mathrm{~S}$ part of the acronym (which refers to two-spirit peoples who are Indigenous to the Americas) 2SLGBTQ is not all encompassing and leaves people to imagine the pursuit of equity. For some, the 2SLGBTQ community has become a beacon of whiteness and co-opting capitalist sponsorship. It has become a place of contention welcome only to certain individuals and their bodies which promote a Eurocentric aesthetic aligning to a Westernized definition of existence. However, for those of us in the margins and in the in-between of each construct, Persons of Colour exist in the periphery. Existence in the realm of the Other disallows people of colour to thrive in the foundations of capitalism. The mechanism of the Other engage a social order compromising the divisional means of existence where the likes of women, people of colour, and queer people experience exclusion (Krumer-Nevo, 2002).

Inviting Two-Spirit and Indigenous identities within language and word use acknowledges the possibilities for including Two-Spirit, Indigenous, and Latinx people among their complex identities from the Native lands of the Americas. In its use, "queer" exemplifies transformative possibilities of language and discourse just as the term "Latinx" constitutes change for Latin American communities. Those seeking to embrace the possibilities of language beyond the boxes of male/female binaries ascribe to "Latinx" use. However, it equally notes a place of debate where Latinx, a gender-neutral term, is not universally recognized among the Latin American community as certain group members choose to use gendered language (de Onís, 2017; Garcia, 2017). It is terms such as "Latino" and "Latina" which have been the standard categories of male and female Latin American persons that inform the logic of coloniality of a European-informed imperial language. As such, movements to use an ' $\mathrm{x}$ ' in the place of a vowel 
strive to highlight a 2SLGBTQ awareness and liberation from imperialist subjectivity (de Onís, 2017; Mignolo \& Tlostanova, 2006). As Latinx compromises gender normative language, Krumer-Nevo (2002) examines the sphere of the Other as a self-imposed descriptor to those existing outside hegemonic consideration of identities. Othering directs a rejection and departure from Eurocentric conditions outlining the leading social class and its beneficiaries (KrumerNevo, 2002).

Mignolo \& Tlostanova (2006) theorize language remains deeply embedded in the epistemology personified in the individual. As one of the six European imperial languages, the Spanish language becomes a tool of colonial difference accounting for colonial production. As a result, a growing movement aims to decolonize and re-imagine language discourse (Mignolo \& Tlostanova, 2006).

\section{Intersectionality, Critical Race Theory, and LatCrit}

An intersectional framework can begin to examine 2SLGBTQ Latin American identities as vastly diverse, ones that entangle colonial subjugation and performance thus including Critical Race Theory (CRT) in discussions. Critical Race Theory posits an inclusion of historically marginalized folks originating in Critical Legal Studies supporting African American groups in the United States (Ladson-Billings, 2003). CRT transforms other realms such as Latinx studies through examining processes of power, privilege, and oppressive forms (Daftary, 2018). In groups formed by legal Scholars of Colour, CRT explores racism known to exist in the American fabric (Ladson-Billings, 2003). Although CRT was not developed for its use in research, it has become a useful theoretical framework to examine oppressive systems beyond applications of cultural competence (Daftary, 2018). Daftary (2018) notes that, in its interdisciplinary foundations, CRT demonstrates the ability to include re-examine social work, sociology, and 
ethnic studies which inform its suitability to serve various disciplines. In this instance, it will produce an analysis to examine social work praxis.

As race is seen as a demographic category for the populace, race has become a concept formed in societal construction rather than a genetic composition. Daftary (2018) states:

Contrary to the dominant narrative that race is an ever-present and fixed reality, the social construction thesis holds that race is a social invention that is constantly changed and manipulated based on the needs of the white dominant group in the United States. (p. 5)

The construction of race as a social invention is further applicable to Latino/Latina/Latinx discussions. A Latinx identity is not seen as a race, but rather as a tangible societal formation basing itself on social, political or financial positioning and processes of prejudice between groups among ethnic and cultural lines. Whiteness is the dominant process which extends privilege to those holding a white identity (Daftary, 2018).

Daftary (2018) examines CRT as an inclusive framework benefiting the research process. CRT has become a grounding method for further development applicable to historically undervalued communal groups. Critiquing race as a construct and its processes signaling discrimination, Latino Critical Theory branches outwardly from CRT as its counterpart centralizing Latin American issues (Daftary, 2018). As LatCrit encompasses the varied and diverse notions of Latin American intersections, it seeks to examine processes of discrimination affecting Latinx persons beyond a lens of CRT where such processes may include topics of language, immigration, and citizenship (Daftary, 2018).

Bernal (2002) further explores LatCrit as a theoretical framework from which to address the multidimensional experiences of Latinidad. CRT and LatCrit converge as a means from which to challenge a dominant discourse founded on Eurocentric values. CRT and LatCrit emerge as counter narratives to Eurocentric epistemologies rather an effort for decolonial 
knowledge (Bernal, 2002). It is the epistemologies rooted in traditional knowledge which encompass approaches of decolonial pedagogies and methodologies for production (Bernal, 2002). In the rejection of a Eurocentric knowledge production, an existence of countermeasures permits other approaches to gain influence in multi-disciplinary practices such as law, social work, and education. Bernal (2002) notes, "CRT and LatCrit give credence to culturally and linguistically relevant ways of knowing and understanding and to the importance of rethinking the traditional notion of what counts as knowledge" (p. 117). In addition, Ladson-Billings (2003) examines CRT as inviting the researcher within the qualitative process, which swiftly opposes traditional quantitative research. As quantitative research has historically implemented processes of dehumanization towards the marginalized and the racial Other, the inclusion of CRT in theoretical and methodological measures further departs from the mainstream (Ladson-Billings, 2003). Within this space, promoting a cyclical and positive intersection of Indigenous ways of knowing while including supplementary measures of Western paradigm results in a Two-Eyed Seeing approach (Knapp, 2013). Two-Eyed Seeing allows two ways of knowing to coincide with one another, thus its implementation in the research process from the inquiry to the implementation of the work completed (Knapp, 2013; Peltier, 2018).

Queer Theory examines discourse surrounding the experiences of Lesbian and Gay individuals: "Queer theory demonstrates a concern with language and sexuality as a form of knowledge" (Hicks \& Jeyasingham, 2016, p. 2359). In subscribing to theories of identity by Michel Foucault, Queer Theory attempts to engage an analysis of language among the discourse of gender, sexuality, and the production of such systems of identity discourse (Hicks \& Jeyasingham, 2016). Queer Theory challenges and problematizes heteronormativity as the set of beliefs that categorize heterosexuality as holding a place of primary privilege (Hicks \& 
Jeyasingham, 2016). The need for intersectional frameworks considering Critical Race Theory, LatCrit, and Queer Theory includes engagements that supports queer, trans, and people of colour experiences confronting white, heteronormative settler discourse. It is through invoking Western and Indigenous ontology which allows for one's reflexivity in the research process and engagement in scholarship informing a place of accordance. 


\section{METHODOLOGY: CHAPTER 4}

\section{Utilizing Participants' Testimonios in Decolonizing the Interview}

For Indigenous learners, voice exists as a medium from which to gather knowledge from knowledge keepers and elders who are recognized as living libraries. Voice has not been regarded as a valid form of research production within historical frameworks for contemporary pedagogy. Research and social sciences scholarship have historically incorporated a ruling course of thought, one that sought to legitimize certain voices over the Other (Tuck \& Yang, 2012). Legitimacy has been given to white settler colonial voices speaking the imperial languages of English, French, and Spanish (Mignolo \& Tlostanova, 2006). Those same voices ascribing to European imperialist conditions become legitimized within mainstream Canadian pedagogy and social sciences in their articulation and thus belong to settler colonialism (Tuck \& Yang, 2012). Tuck \& Yang (2012) and Chilisa (2012) argue that research existing under a complicit positioning of power promotes a refusal for the proposal of an alternative role for the researcher. Gathering participant's testimonios allows for relationality and a newly found connectivity between the researcher and the research participant (Chilisa, 2012). The researcher's role challenges the historical impositions of power through reflexivity and reciprocity in sharing the identity of the researcher, the rationale for the research, and the outcomes of the research produced (Chilisa, 2012).

Entrenched within a system that has opposed relationality and the "Self" which is an integral part of an Indigenized approach to research, I aim to utilize relationality and the "Self" as placeholders for resistance to counter processes of ever pervasive whiteness and historical heteronormative construction. I base queries of praxis through methods of decolonization, critical engagement, and narrative frameworks to forego such limiting and imperialist systems of 
epistemology. In using Critical Race Theory through narrative and testimonios as methodology, I move to re-address means of knowledge production which remove the roles of the researcher and the researched as distinct (Ladson-Billings, 2003). Through such methods, I integrate an ongoing decolonizing praxis, one that transforms through daily engagement with and outside academia. As Reyes Cruz (2008) problematizes notions of decolonial praxis through colonial traditions which marks a colonial gaze, I struggle with such internalized notions of existing for the West or to appeal to the colonial gaze. Reyes Cruz (2008) states this intrinsically challenging position as locating, "Oneself within legitimized intellectual production or at least, speak[ing] like one knows the West and so has the right to challenge it" (p. 656). Thus, advancements for transformative methods for knowledge production become intertwined, messy, and complex within a foundational measure by Western, positivist forms of epistemology. Through a narrative approach empowered by a testimonios foundation, I aim to follow Reyes Cruz' (2008) proposal to include the voices of individuals to produce with rather than for or about colonial subjectivity (Chilisa, 2012). The subjects become and are the academics, the knowledge keepers of their individualized stories and testimonios in existence outside a production of positivist and inherently settler colonial research.

In thinking through methodologies, I looked to subscribe to decolonizing interview methods as Chilisa (2012) demonstrates through invoking Indigenous strategies. Chilisa (2012) notes, "A postcolonial indigenous research paradigm offers other possible interview methods, which privilege relational ways of knowing that valorize respect for relations people have with one another and with the environment" (p. 206). In a decolonizing formation, the self is acknowledged as the researcher. It is through such relational engagement that disruption of current Western values in research are formalized in order to re-consider such positions. The 
distribution of voice for the participants in the interview process informs the autonomous position of the participant in choosing to include their narrative and further assign their respective names to the testimonios shared (Chilisa, 2012). As such, participants were given full authority to establish their engagement throughout the interview process and afterward. Participant were informed of their ability to withdraw up until the final date for revision before publication as outlined in the Consent Form (See Appendix C). In the consent process, a redistribution of power can occur where one can cite the participant as the scholar thus inverting dynamics as a participant's voice informs the decolonial construction of pedagogy. As Fitzgerald (2004) theorizes a disruption of whiteness and its beneficiaries, I pursue forms to dismiss such hegemonic dichotomies labeling the researcher and the researched. As an intersectional body, such dismissal is present in the pursuit of a decolonial subjectivity.

Interrogation of one's own positionality involving the self and constructions of identity informs a place of reflexivity and reciprocity in the research process. A reciprocal and reflexive position informs an active process to decolonize research production and the dissemination of such research. Firstly, regarding one's body as a queer woman of colour intersecting among numerous factors informs the physiological place embodying diverse positionality among its advantages and disadvantages (Calaffel, 2013). To facilitate recruitment, I engaged with community-based social action organizations such as PODER Afro y Abya Yala Fuerza Feminista, a Latinx grassroots and community-led organization, through volunteer work and membership. In online discussions and engagement as a Latin American, Central American, and queer Salvadoran woman, I have come to create a personal reference for community and supportive social engagement. Furthermore, as a migrant-settler on traditional land of the Mississaugas of the New Credit, the Haudenosaunee, the Huron Wendat, and Anishinaabe, I 
continue a personal decolonizing praxis through land and bodily scholarship directing an evergrowing journey for relationality and reflexivity. Without compromising a Mestizo ethnicity, I look to broaden my reconnection with Indigenous heritage through lessons from my Grandmother's lineage from the Indigenous peoples of El Salvador. In serving a relational decolonizing method, I extend gratitude and supportive engagement beyond the interview process to provide support and resources.

\section{Ethics Approval:}

In pursuing qualitative research studies within my own community, the Research Ethics Board posed questions I had not considered in the beginning stages. The board asked about dualrole possibility and the likelihood of identified risks for an already marginalized population. Ethical guidelines were considered in approaching familiar or unfamiliar acquaintances within the Latinx 2SLGBTQ community. Boundaries were upheld to mitigate such circumstances and the Consent to Participate Form was distributed prior to meeting to clearly communicate any potential risks in undertaking such a task with a community member-researcher. Risks were described in writing and I explained that at any given time during the interview or thereafter, participants may choose to withdraw participation.

In the scheduled meeting with participants they were given time to examine the Consent to Participate form and ask any questions. Participants were given the opportunity to use pseudonyms and consented to the use of a recording device during the interview. Given the sensitivity of topics discussed, any identifiable traits or services rendered within the 2SLGBTQ community were withheld for example, any mental health agency disclosed for use of services. As the area of research revolves around experiences within the 2SLGBTQ community and a Latin American background details like ethnicity were included for detailed analysis. 


\section{Recruitment of Latinx Participants:}

Within the recruitment process, I looked to community spaces online and spaces I have built connections with including using a descriptive recruitment poster (See Appendix A) with agencies such as Egale Youth Services (formerly Egale Youth OUTreach), 519 Community Centre, and Stella's Place among online Facebook groups promoting 2SLGBTQ services. Additionally, recruitment posters were shared with contacts belonging to the Latin American diaspora in Toronto.

\section{Questions:}

An interview guide (See Appendix E) was produced to ensure a semi-structured interview method for all participants. An interview guide allowed for a guided structure to gather answers to questions presented to all participants. Questions pertaining to moments or themes of development of their 2SLGBTQ identities were discussed, including: "At what point in your life experiences did you become aware of your gender diverse identity and/or sexual orientation identity?"

\section{Sampling:}

Data collection consisted of interviewing three (3) participants. One on one interviews were conducted with the participants at a mutually agreed upon location. Consent to Participant forms were made available to all three participants ahead of the scheduled meeting time for their viewing and contemplation as shared via email.

\section{Data Analysis:}

Data analysis considered a thematic analysis in a process to find common themes. Four themes were produced to examine internal and external factors contributing to Latinx identity formation. Firstly, ten themes encompassing a person's experience were drafted to outline the 
texts: gender, female/women, community, ethnicity/race, community, sexual orientation, family, male/man, language, and services. Each group was assigned a colour for highlighting relevant text. Eventually, four concise themes were named and formed.

\section{Participants:}

Tobias introduced himself as a trans man of mixed background from his mother's native land of Peru, and his settler father's English and Dutch descent. Tobias acknowledged holding white-passing privilege and complexities intersecting his trans identity within the queer community. In narrating his experiences, he complicated perceptions aligning with heteronormativity in the queer and trans community. Similarly, within perceptions of gender roles and influences of machismo in the Latin American community which assume a man's and a woman's role, he spoke of external perceptions to his transition from his Peruvian family. Tobias spoke of positive reactions and influence from his native family from Peru meanwhile, challenging the imposition of a patriarchal gender discourse by his family.

Natalie introduced herself as a queer woman with a mixed background. She spoke of challenges in navigating various factors with respect to her sense of identity including growing up in a predominantly white town and exploring a distant identity to her South American heritage from Chile. Natalie spoke of the fractured relationship with her Chilean mother and unearthing a connection to Indigenous ethnicity. She spoke of her mother's misconstrued perception of self through a lens of whiteness even among proven roots. Natalie described a yearning to connect with her South American roots, the Spanish language, and seeking community connections to harbour a sense of ancestral understanding and belonging which affirm her queer, Latinx experience. 
Antoinette described herself as an Afro-Latinx, bilingual queer person. She described carving out space for folks of Afro descent within hegemonic Latin American spaces, and the need to re-imagine spaces for Afro and Indigenous persons from Latin America. Antoinette spoke of her sense of identity shaped through engagement with community and activist spaces for folks like her. Antoinette subscribes to an innate, radical position to larger systems of oppression and its processes. Through re-imagination, she described what creation of new spaces looks like. 


\section{FINDINGS: CHAPTER 5}

The testimonios of three Latinx community members comprised the study's findings regarding the identity formation of such individuals. The findings were organised through a thematic analysis searching for common themes including family, gender and sexuality diverse identities. As diverse and non-monolithic identities, the Latinx participants discussed and explored the intersectionality of the Latin American experience beyond hegemonic considerations of nationality, ethnicity, race, and the complex Other. The common themes expressed defined an existence marred through the conditional processes of colonialism. In defining their existence through the in between, the Other, and the intersectional being, the participants explored the rejection of colonial ruling through their mere existence. Four themes were chosen to examine the testimonios presented through intersecting components inscribing the external and internal development of their identity. Firstly, Encountering Canada's Cultural Lines of Ethnicity, Race, and Belonging gathers the participant's experiences as individuals existing on what is called Canada while drawing from Latin American ethnicity including parental ancestry from Peru, Chile, and Dominican Republic. This theme complicates racial lines defining the term Latinx which directed fruitful discussion noting Latinx is not a race but is rather used as a cultural descriptor including their spoken Spanish ability. Whiteness as a colonial concept and European ancestry also intersected within the identities of two participants, complicating privileges attributed to them as a result of real and perceived racial categories.

Secondly, the theme Perceived Gender Roles in Latin America and the Latinx Resistance explores self-identified terms describing the participant's gender, gender presentation, and sexuality diverse identities. The theme explores forms of resisting narratives subscribing to a binary gender discourse which intersects the societal gender roles presented within a Western, 
Eurocentric Canadian society. This theme further explores the presumption of gender roles seen in the Latin American culture, where machismo or a male-dominated societal class is rampant. One participant described his experiences transitioning from being assigned female at birth to male which presented a challenging space informing cultural expectations in the Latin American household and the challenges presenting his new gender role opposing male performativity. Lastly, two themes examining the internal process of development include Identity Formation Through the Internalized Self \& ' $X$ ' Marking the Other, and Beyond a Gender Binary in Latin American Communities \& the Latinx Other. As participants reflected on their personal development, one participant expressed their attempt to unlearn unwanted lessons from a parent, the label of the Other, and examination of the self through such assignment of the Other. Within such process, this participant spoke of the nascent discovery of familiar and ancestral learning, one taking formation through engagement with a native South American land and informative discussions with a community member.

\section{Theme \#1: Encountering Canada's Cultural Lines of Ethnicity, Race, and Belonging}

All three participants disclosed mixed heritage with two participants, Tobias and Natalie describing European ancestry as well as having a parent of Latin American ethnicity. Tobias disclosed his mother's Peruvian ethnicity while describing his paternal family as settlers with English-Dutch background. In complicating racial lines, he stated: "I identify as a Latino man, but I also understand depending on whether or not I have a tan I'm generally white-passing" (Tobias). Beyond conforming to racial discourse and ethnic grouping, skin privilege within the Latin American community runs deep and affects the relationality participants describe as having with the Latinx community of Toronto. A second participant, Natalie, described her mother's complicated and internalized comprehension of the self as subscribing to whiteness as the ideal: 
Her vision of life for me was always as a white person, and that she sees herself as white...she so badly aspires to be because that was labeled for her as the pinnacle of success and achievement and once she can achieve those things... More tangentially are connected to whiteness as an identity not necessarily as an actual physical colour but what it relates to, speaking English without an accent, whiteness equates to holding a steady job, whiteness leads to having a home, having a car, having a family, being married; these are all things ascribed to whiteness which then meant heteronormativity was also ascribed to whiteness. (Natalie)

An examination of privilege and discourses of whiteness in language, gender presentation, and gender expression allows certain bodies to navigate LGBTQ spaces with more ease than others (Giwa \& Greensmith, 2012; Greensmith, 2018). Tobias described his white-passing privilege intersecting with his gender presentation as a weight compounding his involvement in the queer community, "I have white-passing privilege as well as having physically transitioned... a lot of people, as questionable it is to say, 'You don't look like you're trans' also comes into play as my trans-status isn't immediately recognizable" (Tobias). These arbitrary lines of ethnicity intersecting presumed 2SLGBTQ identities further divide and assign descriptors to what it means to be queer or trans. Participants note the degree to which arbitrary grouping based on race or ethnicity affect service provision and access to space depending on the body you present, "I would say once that the trans status is known, I have definitely felt that suddenly I was treated differently by certain people" (Tobias).

Antoinette presents her identity as an Afro-Latinx or Afrodescendiente. Within the queer community Antoinette describes carving a space for her intersecting identities among other folks: "It was really within the queer community that I discovered Afro-Latinx people were a thing" (Antoinette). This speaks to the inaccurate painting of Latinx or Latinidad as a race because a Latin American identity can intertwine among diverse ethnic lines beyond influences of European colonization. Antoinette describes her perspective on the term Latinx as complex and as a starting point for gender diverse language in the Spanish context: 
I use it as Afro-Latinx and if people ask, then it's like this is where my intersection comes in. In the Black and Spanish... having family from the South. It's definitely been a term that I use to describe my ethnicity, not so much my race. I don't use it at all as something to describe race because there is white Latinx people... there are Black and Indigenous, Asian Latinx people. (Antoinette)

As two participants disclosed their European ancestry, self-described privileges of whiteness presented an authentic point of discussion. A presentation of whiteness among a mixed ethnic background provides a place of examination in assuming an ancestral heritage from Latin American countries, meanwhile complicating conditions that afford complicity as a whitepresenting body. In refuting historical narratives excluding minority voices within Latin America, Antoinette voices a common theme that has erased Indigenous or African descendants within Latin American spaces and discussions which further prove the need to build such scholarship.

\section{Theme \#2: Perceived Gender Roles in Latin America and the Latinx Resistance}

Gender in the 2SLGBTQ community appears as fluid and diverse. Gender may become a point of resistance to a societal gender discourse ascribing to a binary composition between 'man' and 'woman'. All three participants complicated this binary. Gender expression presented as deeply personal for the participants with participants disclosing factors of influence from society to family systems affecting such expression. In asking the question "Can you tell me about some of the success and challenges in forming your current identity expression?" Tobias stated the macro-level influence on his gender identity as having a large impact, "I would say the social, highly binary gendered norms and expectations can make it very difficult to form that [male] identity". Tobias further confronted society's unwritten gender norms as potentially distressing in nature:

There's almost this internal pressure if you want to adopt a male identity or want to be recognized as having a male identity. You have to cast out anything feminized in society whatsoever, so it means no more playing with cute little duckies. None of that stuff 
anymore, you got to let all that go. It can be really distressing for a lot of people. I think that it makes you doubt your gender identity, but I still love the cute duckies. I love them and want to hug them and kiss them. Does that mean making my male identity invalid? (Tobias)

In similar fashion, Tobias states transgender women also face highly gendered, hyperfeminized societal expectations compounding pressures to conform to ascribed gender expression. 2SLGBTQ persons in their interpersonal relationships are likely to experience heightened risk levels based on perceptions and reaction to gender presentations. Travel, as a form of engagement with new environments, may present a real risk to LGBTQ couples as Natalie notes in discussion with a community member, "Let's talk about the places for you and your trans identified partner to travel...because that is legit risky, kind of like misogyny and advances on your body as a femme and someone who is read as Latinx in that space" (Natalie). In discussions, 2SLGBTQ bodies and gender presentations exemplify paths of resistance rejecting heteronormative functions of society. Additionally, 2SLGBTQ individuals augment the spectrum of identities in their fluid nature. Antoinette describes her identities as ranging between life cycles, “...In my high school years I was maybe thinking I was a lesbian, after college I was like 'Yeah, no, I'm queer' or at the time bisexual”' (Antoinette). Furthermore, in examining an identity void of heteronormative constraints she states:

I have not remained stagnant whatsoever, for instance, my sexuality has changed depending on how I've grown. I've gone from being lesbian to bisexual/pansexual to naming myself as queer, just to let people think whatever they think but I'm just gonna be like, "No, I'm queer". I don't have to define it, it's going to be fluid, it's not something I need to define or stay with.

In discussion with the three participants, queer and transgender identities were determined to be fluid, and non-conforming to heteronormative standards of existence. Whether diverse gender and sexuality was a topic of discovery early in age or later in adolescence and adulthood, it is clear the participants did not uphold a stringent consideration for binaries. For example, Tobias 
and Antoinette describe their queer identities blooming during high school ages. Tobias noted his early identity forming through questioning of his sexual orientation:

It wasn't until high school that I realized that I was sexually attracted to women, so at that point I identified as a lesbian until the age of 14 to the age of around 19. That's when I came in contact with the greater scope of the queer community... came across a couple different trans folks, "Oh, this is what's going on". Then when I was 19 early 20, when I socially transitioned and went, "Okay, I'm a transgender man and that makes sense. (Tobias)

A common factor affecting the participants' diverse identities was the impact of socialization on defining 2 SLGBTQ identities both within families to larger impacting systems including the internalization of homophobia. Antoinette identifies one instance of internalized homophobia affecting her ability to recognize a queer identity:

I was really close to one friend in particular and I remember them asking me if I was queer and at the time, I had a lot of internalized homophobia. I was like, "No, no, not at all"...I didn't want to admit it. (Antoinette)

Tobias, Antoinette, and Natalie described early life development as having an impact on the formation of queer and trans identities where such development informed the social conditions both in negative and positive regards to affect an individual.

\section{Theme \#3: Identity Formation Through the Internalized Self \& ' $X$ ' Marking the Other}

As intricate beings, the three participants note processes of identity development from a myriad of experiences. Once his trans and male identity came to fruition, Tobias was subjected to new sets of perceived gender discourse within the Latino family structure, "It's funny because my trans and my male gender identity was accepted and then there's a whole new set of performances, so it's like 'Oh, okay, you're a guy' so that means you have to start doing X, Y, and Z" (Tobias). In comparison, Tobias describes his Latinx family's inclusive reaction as means for gender affirming experiences and ones of empowerment. In reporting an instance of growth in his environment Tobias describes: 
I would say having support from family members over time has been an empowering piece. I'm thinking recently when I went to Peru in March for my Grandparent's $50^{\text {th }}$ wedding anniversary and having the family members in Peru... I was dancing with my abuelitas, tias, and stuff like that and being accepted in that way was a huge boost. (Tobias).

As participants describe their familial relations engaging with experiences of their diverse identities further discussion determines the weight of external courses of exclusion causing internal challenges. As a person of mixed heritage, Tobias' influence from Latin American and Eurocentric cultures presents a contentious place of influence. Within those places of ambiguity, the participants were able to identify positive aspects for connection with their respective ethnic backgrounds. Tobias describes his growing sense of belonging with the Latinx community:

I think that I'm more comfortable now than previously but I still think because of my particular middle-ground intersection it's always hard cause I know for myself, again with visibility of ethnic background and having rudimentary Spanish skills but not fluency and I think that the language piece can be a big barrier a lot of the times. I definitely feel having made friends in the community has helped with that integration as well. (Tobias)

In examining her ethnicity and cultural formations intersecting an ability to hear her voice represented in 2SLGBTQ spaces, Natalie explains a confluence discovered deep within ancestral understanding of a distant connection to Indigenous roots from Chile. In seeking information from her maternal family and connecting to Chile, Natalie describes blood memory as the connection traversing land for an embrace of ancestral foundations (S, V. M., \& Sánchez, 2003):

It's also that feeling that you've missed pieces, but things feel familiar. If I visit a country with predominantly a Spanish speaking population in Central or South America, there is something that feels familiar, there's something that feels comforting in a way that I can't articulate yet. (Natalie)

Antoinette bore her identity through the present connection rather than any potential influence from factors of race, ethnicity, and culture. Rather, Antoinette describes connections with similar and like-minded individuals as informative. Antoinette stated a sense of attachment to the 2SLGBTQ community mostly to community members embracing Black, Indigenous, and People 
of Colour (BIPOC) identities, "I sense an attachment for those that share my story of mostly BIPOC folk or people that understand what BIPOC folk are still going through within this community" (Antoinette). Antoinette further identifies the politics embattling the 2SLGBTQ community in Toronto, she noted:

I'm probably not going to identify very much with people who are shouting and bashing Black Lives Matters when they did the protest [Demonstration of halting Toronto's Pride Parade in 2017] ... You don't get that there is still over-policing of Black, Indigenous, queer, and trans people. Black folks are still over-policed here, you're yelling at Black Lives Matter for addressing for addressing the issue. (Antoinette)

Thus, formulating an identity through experiences of life and social development within one's demographics have a compounding affect on Latinx people. Lastly, a fourth theme was produced to examine community as a decisive factor influencing identities and their diverse formation.

\section{Theme \#4: Beyond a Gender Binary in Latin American Communities \& the Latinx Other}

Latinx has been identified as a nascent term describing Latin American gender and sexuality diverse community members. As such, it has become a place of contention between linguistics versus those seeking inclusive space. Participants were asked an additional question regarding the term. Participants presented their perspectives noting such contentious discourse.

The Latinx community in Toronto has presented 2SLGBTQ individuals a space to celebrate the rainbow spectrum and their Latin American heritage. Tobias examined the term's potential to direct the possibilities for linguistic expansion:

I have done a little reading on lots of different articles from folks that have different viewpoints. I feel like the idea or the concept of opening up a very binary language like Spanish...everything is male or female. It has an $\mathrm{O}$ or an A at the end of it. Opening it up so it's not so restrictive is a good concept but I have read on opposing or different ideas of how to go about doing that. Some people think that Latinx goes far enough, some people think no there's a particular historical root and there shouldn't be $\mathrm{X}$ in the end, it should be something else or some people then go it's just dividing things in three, $\mathrm{X}$ is the whole spectrum. I think it's a start in the right direction in the very least. (Tobias) 
Natalie shares similar sentiments problematizing the Spanish language for its gendered

processes:

It always bothered me in trying to learn Spanish that things are gendered as a small child when I went to Spanish school... contrary to those naysayers that my mother did a bad job parenting me, she actually tried to send to Spanish language immersion classes on the weekend which I hated cause I was trapped in a room with twenty other ten year olds who were studying everything from German...It always really bothered me. As a very young child I was, "This is super messed up", why is a table, why are we feminizing things that are less than. It's very apparent to me as a young person and a hardcore feminist from a very young age like standing up at dinner and telling them at eight years old that I did not need a man with a lot of money cause I was going to make my own money. (Natalie)

In formation of community spaces, language becomes a place of inclusion and exclusion. One may identify with a certain term in the 2SLGBTQ acronym or connect with a common language. It is through reflection in the borderlands that the participants interviewed examined areas of community and the future for community building. Antoinette describes Latinx as, "A useful term for now, there is definitely room for change". One can note language discourse as evolving and ever-growing, much like identities.

In forming community relationships, the participants described various positions in the Latinx community. In her involvement with a community led Latinx organization in Toronto, Antoinette defined diverse intersections as places of resistance within the Latinx community itself. In considering recommendations for change, Antoinette saw radical resistance from silenced voices, “A lot of Latinx people taken down from positions of power they've taken specifically for Latinx people... That's great but these are positions that should be held for Indigenous people or Black people who are going towards their own communities". As political bodies facing both negative and positive impacts, the participants describe utilizing positive community engagement in their healing journey. Antoinette describes attending a therapy group 
for queer, trans, and BIPOC people, which provided a space among the comfort of community members:

I learned a lot from every single person that was there cause we all not only had the same intersection, dealing with similar things everybody with something different but some of us dealing with suicidal thoughts, some of us dealing with immigration issues...(Antoinette)

Antoinette further describes the benefits growing from her community foundations, "I really appreciate that finding my community helped with looking for other resources... when it comes to mental health”. In conversation, Natalie described a deep connection with an individual of a Latin American heritage as a place for affirming her identity:

The most affirming experience I've had in recent memory, kind of encompassed all elements in trying to navigate my own identity through a clinical supervisor that I used to access in a different workplace. She identified as a queer femme probably fifteen or twenty years older than myself from South America... It really felt like talking to my aunt but if my aunt were queer and had all the language around queer identities and trans folks and dating people or loving people who don't fit with your family's ideas, conceptions of partnerships, and ideas on who's acceptable and appropriate with gender. (Natalie)

In consideration of community participation, the individuals describe their consideration for the social work field and the role of service providers in their immediate environments. In examining the creation of space, Tobias presents a positive prospect for change alongside a critical analysis for future consideration:

I think it can definitely be a positive piece especially the positive piece, advocacy, and the consciousness raising and awareness. I would be cautious falling into the trapping social work which is conforming to institutional stuff yet again or we are going to create this new institutionalized niche. We'll add another box to the paper but that's not the issue that there isn't enough boxes to tick off on the paper, it's that there's boxes in the first place. (Tobias)

Similarly, Antoinette offers a radical approach to social work processes which could promote inclusivity in Latinx community work, she notes:

I kind of think that a lot of these roles are important but I wish they weren't, I wish we didn't have to have these roles exist... In order for social workers or social service 
workers to exist and non-profits to exist, we need poor people. It's kind of maintaining what we have. It's just like this is a band-aid solution. (Antoinette)

It is within community spaces where 2SLGBTQ individuals thrive. As research notes, 2SLGBTQ individuals experience processes of exclusion and discrimination often beginning within family homes. In seeking and discovering community, 2SLGBTQ people find spaces of inclusion. Participants note their understanding of a Latinx discourse as it pertains to their experiences among discovery of community. It is within these same spaces of community where further action is needed to include voices of the knowledge keepers and the silenced among such spaces. Radical resistance begins with the voices of Black, Indigenous, queer and trans Latinx people. 


\section{DISCUSSION: CHAPTER 6}

As Kimberle Crenshaw presents intersectionality as a framework from which to examine underrepresented individuals, it is Black women, transgendered women of colour, and queer people who have advanced epistemologies. Gloria Anzaldúa notes the borderlands as a place of strength for her Mestiza identity as Emma Pérez presents queering the borderlands, "To disidentify is to look beyond white colonial heteronormativity to interpret documents differently" (Pérez, p. 124). In transformative actions, the participants interviewed expressed their testimonios as inherently rejecting white heteronormativity. Two of the participants expressed their complex livelihood entrenched with processes of white privilege as persons with mixed Latin American heritage. In examining their white privilege, the participants complicated connections and their relation to ancestral lines. Existing as multi-layered beings, the participants expressed their testimonios through formations of queering the borderlands and rejecting a binary discourse. Within the Latinx community in Toronto and 2SLGBTQ spaces, the participants examined various areas of engagement. It is through discussions of transcending space that the participants explored their personal resistance to traditional notions of gender, sexuality, and identity.

Four themes were identified from the interview transcriptions to gather and explore Latinx identities. The themes were broadened from categories of internal and external factors affecting an individual. The themes examine social and demographic groups connecting various facets of the Latinx experience including gender, sexual orientation, and community. It is within reflexivity and engaging the "I" where fruitful discussions present such complexities to an existence. Calaffel (2013), considering spaces of advantage and disadvantage suggests that, "These spaces, in their complexity and multiplicity, call us to be accountable to others and to 
ourselves in marking the workings of power" (p. 7). Interrogation of power and oppression present various facets to the Latinx resistance. Power holds a diverse construction further complicated identity formation. The Latinx existence challenges definitions of power discourse which engage complex consideration for distinct analysis in research. A participant noted a distant embrace of a familiar land where blood memory described Natalie's connection to the Global South even throughout recognizing a fractured sense of a Chilean nationality. Settlerhood depicted a littered relationship with land engagement which further complicated an analysis of power as diverse ethno-racial beings.

Identity born from an inherent difference to designated inscriptions of a gendered body further presented a place for analysis. Gender as an assigned marker and place of expression proved to intertwine in one's formation through internal and external influences. Participants noted that a gender identity presents an attachment to societal discourses of engagement that are both positive and negative within close environments. Through engagement participants disclosed possibilities of a Latinx identity as more than survival but a place of celebration as diverse beings.

\section{Implications for Research, Social Work, and Practice}

Participants were asked about implications for social work and social services practice, as all have experience dedicated to service provision for Black, Latinx, and 2SLGBTQ communities. In examining identity formation, participants challenged historical and exclusionary practices from what could be a noble profession. Participants expressed gaps in services needing to swiftly transform to aptly and appropriately serve the community. Future research requires careful consideration of all intersecting identities. Reflexive engagement by LGBTQ service providers can foreground Indigenous praxis and pedagogy for the benefit of 
ALL. A decolonial and Indigenous praxis inherently rejects the lens of colonial or capitalist ruling, creating a system that better supports 2SLGBT Latinx beings. Latinx individuals may have Indigenous and ancestral ties while simultaneously existing as colonial beings in the past and present. At this point, there is a place for a Two Eyed Seeing approach to engage in harmonious directives for change where decolonizing and decoloniality must be adhered to in the research process and praxis among certain Western inheritance in scholarship. Queer Theory must acknowledge it's functioning from a place of colonial subjectivity. Whereas Smith (2010) argues for construction of a queer theory beyond inscriptions to "humanity", one that promotes duality within the queer and the Native, "Native particularity cannot achieve universal humanity without becoming 'inauthentic' because Nativeness is already fundamentally constructed as the 'other' of Western subjectivity” (p. 42). In doing so, a queer theory which engages with settlerhood is further needed among approaching frameworks to unsettle colonialism (Smith, 2010).

It is within socially constructed discourse of gender, sex, and race where transformative possibilities can be produced or altogether rejected. As participants note, the social work field fails in imagining itself outside of the traditional, historical, and constitutional. Intersectional bodies in the borderslands exist in the shadows. Fields like social work may contribute to categorizing the Other and the atypical, where Latinx bodies exist outside the ordinary. A need for examining all the endless possibilities of the Latinx 2SLGBTQ person is warranted to truly consider the nuances and varied characteristics. As one participant noted, their experience is anything but rigid and dense. Such reflexivity in embracing the chaotic allows for possibilities of decolonial processes which were presented in embracing the "I", in the researcher's role, and the inclusion of participant's narratives in their authentic voices. 


\section{Relationship of Results to Theory}

Through subscription to decolonial processes and intersectionality, theories of Critical Race, LatCrit, and queer theory were presented and examined in the results. The theories adhered to were omnipresent in the narrative testimonios. In the testimonios, discussions of societal discourse were challenged through fractured sense of identity among discovery of a resistant being. Race was understood as a construct attempting to define a person's experience through migration, settlerhood, and resistance. It was in critical moments of self-reflection where certain participants navigated the complex and messy intersections. In reflecting on a multi-layered Latin American identity, the participants were able to define the nascent term "Latinx" as it is defined through intersections of social place, assigned and deconstructed gender roles and the Other. Academic theories were able to supplement notions of understanding an identity. However, as one participant discussed, academia can be limiting and exclusionary thus requiring further presentation of a heuristic approach beyond "logical reasoning" presented in popular academic and research processes. The Other presented an authentic and diverse meaning to identity formation for Latinx individuals in their existence beyond white, cis, and heteronormative confines.

\section{Limitations:}

As an overarching theme, intersectionality continues to forego traditional consideration to pedagogy. With a small-sampling size of three participants, intersectionality was only addressed as far as the intersections of the testimonios presented. As one participant noted, Latinx and a Latin American identity can comprise various ethnic compositions beyond South and Central America. For example, a person can exist as an Afro-Latinx, Asian Latinx, Indigenous Latinx person or a non-denominational or Muslim Latinx identifying individual. Given the specificity of 
study requirements, seeking Latin American individuals aged 18 years of age of older, and selfidentifying member of the 2SLGBTQ was challenging, more so than I had imagined. As I identify as a queer Latinx femme, I sought spaces and avenues for engagement in physical spaces that I know Latinx people occupy and through online spaces through community networks. Nonetheless, reaching participants was a challenge. As a community member, the three participants were known from spaces of employment or community organizing spaces in the 2SLGBTQ community, and Latinx community engagement.

In seeking academic sources, few studies encompass Canadian experiences of Latinx individuals with only a handful of basing research from such a perspective. Nonetheless, works cited included community members conducting such work in the City of Toronto. Further decolonizing practice and engagement can produce work centring the voice of ancestral knowledge on Indigenous land. An attempt was made to begin this work among notions of challenging settler colonialism. A continuation of decolonial praxis in research methodology to pedagogy further calls on direct action for educational institutions to note such critical work among education initiatives for the benefit of Aboriginal Canadians, and non-Aboriginal Canadians (Truth and Reconciliation Commission of Canada, 2015). 


\section{CONCLUSION: CHAPTER 7}

The term "identity formation" was chosen to simplify wording for an intricate process. Identity formation for Latinx individuals intersects with various facets of existence. Whether constructions of race or race privilege in and outside the Latinx community, participants exposed complexities of their lived experience. Participants narrated the time and spaces stabilizing or destabilizing impacts to their Latinx and queer selves. Through processes of critical reflexivity as a Latinx, queer, femme, person of colour, and Other, I was graciously given consent to conduct an examination of self, a recording, and written product in the dissemination of this MRP. The participants discussed formations of the self through perspectives of the internal and external. Internal processes of identity through impacts of examining the queer self promoted ideas of the personal as diverse; meanwhile, participants heeded reflection of the external processes of societal and familial expectations to living and thriving in queer bodies. Participants embraced and questioned intersecting ethnic formation from distinctive Latin American countries and their cultures that embody language, gender roles or navigating a resistance to traditional facets of such language and gender roles. Spanish, as a primary language utilized in Latin America, proved to be a site of contentious engagement as it performed as an extension of coloniality and an invisible and linguistic barrier. As speakers of a colonial language, Spanish and Hispanicidentifying persons can uphold a colonial grasp that excludes non-native speakers, as participants noted. Language as a discourse surrounding terminology was equally noted as a mechanism for space and inclusion whether a person can identify their labels to categorize an identity existing outside the straight, white, or cis-gender in the 2SLGBTQ+ umbrella. Thus, gendered terms such as Latino and Latina have been rejected by those in such support for movements embracing gender and sexually diverse Latin Americans. Additional terms like Latine, Latin@, and Ladino 
grow to encompass a Latin American diaspora that is inclusive of 2SLGBTQ persons (Garcia, 2017; Milian, 2017). As the term Latinx grows outside its origin, it has become a place of contention that complicates notions of linguistic capabilities and tenets of social justice for Latin American persons (de Onís, 2017). I move to re-imagine a personal post-Latina discourse inclusive of ancestral teachings as I look to discourses encompassing identities, I have come to establish such as a gender non-conforming identity that is personal to me. As Pérez (2003) outlines shifting epistemologies, they note assuming a practice that dispels and challenges rhetoric basing colonial, white, and heteronormative discourse as the norm. In producing a paper with, for, and by Latinx voices, I aim to conduct research methodologies that assume my voice within the research. It is through decolonial engagement that I aim to present the self in relation to the research produced. It is beyond constructions of uniform labels and boxes where further examination can highlight the extraordinary as Latinx people in the 2SLGBTQ community in Toronto can be anything but ordinary. Acknowledging individuals before me, I embrace the internal from the ancestral that shape such directives. With my abuelita [grandmother] in mind, I aim to aprender [learn], escucha [listen], and actuar [act]. It is through processes of learning through personal and land pedagogies from spaces of my birth to settler occupation where I continue to strive for a place of transformative influence. 
Appendix A - Recruitment Poster

\section{Ryerson University}

\section{RESEARCH PARTICIPANTS NEEDED}

\section{Existence as Resistance in Tkaronto: Identity formation for Latinx LGBTQ People}

Do you identify as Latinx and part of the LGBTQ (lesbian, gay, bisexual, transgender, queer) community in the city of Toronto?

What: A two hour opportunity to share your story in regards to your identities and experiences within the community in the city. Participants will be interviewed to examine their experiences with Toronto's LGBTQ community meanwhile, navigating intersections of self-declared race, ethnicity or cultural groups within the Latinx community.

Why: This study seeks to understand how the experiences of members of Toronto's growing Latinx community and if they have any significance on identity formation through inclusion or exclusion practices. In addition, what aspects of identity formation over the course of LGBTQ lifespans help shape navigating such intersectional identities.

Who: To participate you must meet the following criteria:

- $18+$ years of age

- Self-identify as a Latinx person (Latin American cultural or racial identity heritage)

- Self-identify as a member of the LGBTQ community in Toronto

- Currently living in Toronto

Where: Ryerson University - Student Learning Centre or other mutually agreed upon location ensuring privacy. Further details will be given once selected.

Compensation: In consideration of your time, participants will receive an honorarium of a $\$ 10.00$ gift card and reimbursement of TTC transit fare costs. Contact for details.

For more information or to participate, please email Martha Segovia: martha.segovia@ ryerson.ca 
Appendix B - Facebook Post

Facebook Recruitment Post:

Do you identify as Latinx? And part of the LGBTQ (lesbian, gay, bisexual, transgender, queer community)?

Martha Segovia is a Latinx graduate student looking to sit down with folks from the community. This study seeks to understand how your experiences of Toronto's LGBTQ communities has, if any, significance on your identity formation through inclusion or exclusion processes as a Latinx person.

If you are interested in learning more or potentially participate in this study, please email Martha Segovia: martha.segovia@ryerson.ca 
Appendix C - Consent to Participate Form

\section{Faculty of Ryerson Community University Services}

\section{Ryerson University}

REB \#: 2019-084

\section{Consent Agreement}

You are being invited to participate in a research study. Please read this consent form so that you understand what your participation will involve. Before you consent to participate, please ask any questions to be sure you understand what your participation will involve.

\section{Existence as Resistance in Tkaronto: Identity formation for Latinx 2SLGBTQ Persons INVESTIGATORS:}

This research study is being conducted by Master of Social Work student, Martha Segovia, supervised by Assistant Professor, Jeffrey McNeil - Seymour of the Faculty of Community Services, School of Social Work at Ryerson University.

If you have any questions or concerns about the research, please feel free to contact Researcher, Martha Segovia at martha.segovia@ryerson.ca or Research Supervisor, Jeffrey McNeil Seymour at jmcneilseymour@ryerson.ca

\section{PURPOSE OF THE STUDY:}

This study is designed to explore the experiences of Latinx persons who also self-identify as a member of the 2SLGBTQ (Two-spirit, lesbian, gay, bisexual, transgender, queer) community.

Participants will self-identify as Latinx and members of the 2SLGBTQ community in the City of Toronto, 18 years of age and older. The study will interview 4 - 6 participants. This research proposal has been reviewed by the Ryerson REB. This study is being done as part of the researcher's graduate studies for the partial completion of the researcher's degree.

\section{WHAT PARTICIPATION MEANS:}

If you volunteer to participate in this study, you will be asked to do the following things:

- In a single, one-on-one interview session, you will be asked to share your experiences forming your identity as a Latinx person in the 2SLGBTQ community in Toronto.

- The researcher seeks to listen to your experiences and narratives surrounding factors of self-identity formation and access to 2SLGBTQ safe spaces in Toronto.

- The expected duration of the interview is two hours, the expected meeting locations are Ryerson University's Student Learning Centre at 341 Yonge St, in a private Study Room or the GRADSpace facility at 111 Gerrard St. East. 
Participants can expect interview questions such as the following:

- At what point of your life experiences did you become aware of your gender diverse identity and/or sexual orientation?

- Can you tell me about specific influences from your racial/ethnic/cultural background that inform your gender identity and/or sexual orientation?

Data gathered through the interview process (transcripts, paper forms only) will be obtained for one year if authentication needed. Data will then be destroyed through shredding, erasing and disposing of paper files in a confidentiality waste bin at Ryerson University after the one year. The primary researcher and researcher's supervisor to have access to materials and data only.

Data will be disseminated through class presentations (at Ryerson University, York University and/or University of Toronto lectures). This MRP will be published as a journal article. In professional pursuits of scholarship, I will apply to present at conferences, such as the Annual LGBTQ Research Symposium: An Interdisciplinary Symposium on LGBTQ Research in the Social Sciences for presentation and Latino Social Workers Organization conferences.

Research findings will be made available to you through a link to the Ryerson Digital Depository to access major research paper at your own discretion once completed.

\section{POTENTIAL BENEFITS:}

In centring your narratives and testimonials of your identity, the research will provide the space and time to lessen feelings of isolation and discrimination through such sharing of identities that may inform positive self-reflection during the interview, development of your resiliency as diverse individuals and provide concrete examples of your journey to be commemorated in the final completed research paper.

I cannot guarantee, however, that you will receive any benefits from participating in this study.

\section{WHAT ARE THE POTENTIAL RISKS TO YOU AS A PARTICIPANT:}

Participation in this study is low risk. You may experience discomfort when asked and answering questions in regards to your gender identity and/or sexual orientation. For some, sharing these experiences may be difficult and may result in feeling upset or uncomfortable. Participants are reminded they can take breaks, skip questions or stop participation, either temporarily or permanently. Community resources will be made available in order to attend to feelings of stress or tensions as a result of your involvement in this study. There is a potential for social risk if your identity is revealed, specifically if your sexual or gender identity is disclosed to a third party. The research may involve low physical risk for participants in their presentation of their authentic self. Protection of your identity is discussed below. Other noted potential risks to participation may include:

- You may experience discomfort when asked and answering questions regarding your gender identity and/or sexual orientation. Participants will be casually checked in with should they need a break during our time together.

- There is a potential for social risk if your identity is exposed, specifically if your sexual orientation or gender identity is inadvertently disclosed to a third party. There is a 
potential risk for direct or unintended revelations of participant's personal identity given the small nature of the 2SLGBTQ community in Toronto. The measures to be taken to protect your identity for such risk include choosing pseudonyms (fake names) to be assigned to you if you chose to be given a pseudonym. Other potential identifying information, for example, names of social spaces and locations accessed will be censored.

- Self-disclosure and 2SLGBTQ identities have been and continue to be a decision most persons in the community must consider for example, in areas of employment and on. Similarly, if financial risk is presented a pseudonym (fake names) can be assigned to you if you chose to be given a pseudonym.

\section{CONFIDENTIALITY:}

Extensive measures will be taken to protect your identity in this study. If you choose, pseudonyms (fake names) will be assigned to you. Other potential identifying information, for example, names of social spaces and locations accessed will be censored.

Personal information including date of birth and address will not be recorded. Information provided by you will only be viewed by the researcher and the researcher's supervisor, and if necessary, transcripts with no identifying information will be shared with the supervisor. Information will not be accessible to any other parties. However, I must adhere to professional duties to report where, on reasonable grounds, the disclosure of imminent harm to the self or risk to another, and/or disclosure of child abuse is discussed.

The interview will be audio recorded if you chose so. You will have the ability to review the transcript and provide edits. Audio will be recorded on a protected device, where it will be transferred to a password-protected computer. The audio file on the voice recorder will be destroyed immediately after the transfer, while the audio file on the computer will be destroyed once the transcript has been verified by you.

Data gathered through the interview process (transcripts, paper forms only) will be obtained for one year in case of authentication needed. Data will then be destroyed through shredding, erasing and disposing of paper files in a confidentiality waste bin at Ryerson University after one year.

\section{INCENTIVES FOR PARTICIPATION:}

An incentive to participate in the study includes a $\$ 10$ Walmart gift card for in-person interviews.

\section{COSTS TO PARTICIPATION:}

Reimbursement of bus tokens to be provided to you as the research participant. Other costs of participation including parking and gas will not be reimbursed.

By agreeing to participate in this research, you are not giving up or waiving any legal right in the event that you are harmed during the research.

\section{VOLUNTARY PARTICIPATION AND WITHDRAWAL:}

Participation in this study is completely voluntary. You can choose to be in this study or not. If any question during the interview makes you uncomfortable, you can skip the question. You may 
stop participating at any time and you will still be given the incentives and reimbursements described above. If you choose to stop participating in the interview, you may also choose to not have your data included in the study. Participants may withdraw their data up until final revisions deadline as postulated by Ryerson School of Social Work on July 30th.

Your choice of whether or not to participate will not influence your future relations with Ryerson University, the investigators, Martha Segovia or Research Supervisor, Jeffrey McNeil - Seymour involved in the research.

\section{QUESTIONS ABOUT THE STUDY:}

If you have any questions about the research now, please ask. If you have questions later about the research, you may contact Martha Segovia at martha.segovia@ ryerson.ca or Jeffrey McNeil - Seymour at jmcneilseymour@ryerson.ca

This study has been reviewed by the Ryerson University Research Ethics Board. If you have questions regarding your rights as a participant in this study please contact:

Research Ethics Board

c/o Office of the Vice President, Research and Innovation

Ryerson University

350 Victoria Street

Toronto, ON M5B 2K3

416-979-5042

rebchair@ryerson.ca 


\section{Existence as Resistance in Tkaronto: Identity formation for Latinx 2SLGBTQ Persons CONFIRMATION OF AGREEMENT:}

Your signature below indicates that you have read the information in this agreement and have had a chance to ask any questions you have about the study. Your signature also indicates that you agree to participate in the study and have been told that you can change your mind and withdraw your consent to participate up to July 30th to meet researcher's final date of revised paper. You have been given a copy of this agreement.

You have been told that by signing this consent agreement you are not giving up any of your legal rights.

Name of Participant (please print)

Signature of Participant

Date

I agree to be audio recorded for the purposes of this study. I understand how these recordings will be stored and destroyed.

YES

NO

I agree that my real name can be used for quotes:

YES

NO

Signature of Participant

Date 
Appendix D - Demographics Form

Data Collection - Demographics Form:

Existence as Resistance in Tkaronto: Identity formation for Latinx LGBTQ People

This study seeks to understand how your experiences as a Latinx \& 2SLGBTQ person and if any factors in your lifespan have had any significance on your identity formation through inclusion or exclusion practices

This form is to recruit voluntary participants who self-identify as Latinx and self-identified members of the 2SLGBTQ community, who are 18 years of age and over, residing in the Greater Toronto Area.

If you choose to participate in the filling of this form to ensure this study meets your identity and interests please note your contribution via this form will remain confidential, as all forms will be safely stored.

Name:

Age:

Email:

Phone Number:

Pronouns: He/His:

She/Hers:

They/Them:

Other:

I Identity My Ethnicity As:

Latin American:

Hispanic:

Other:

Are You a Member of the 2SLGBTQ (Two-Spirit, Lesbian, Gay, Bisexual, Transgender, Queer Community?

Yes:

No:

I Identify My Gender As:

Female:

Male: 
Nonbinary:

Other:

Would You Describe Yourself as Transgender?

Yes:

No:

Prefer Not to Say:

Other: 
Appendix E - Interview Guide

Martha Segovia

\section{Interview Guide}

1. Introductions: (After reading and signing the consent form) Thank you for agreeing to share your story with me, I am deeply honoured and humbled for the gift of your time. I would like to reiterate that at any point during the interview process you can stop the interview and its recording at any point. Once in the publication process, you will retain the right to withdraw from the study. I have questions to help move the conversation along and to aid you in the telling of your story. You are free to answer as few and as many questions as you are comfortable with, you may decline to answer any of these questions at any time. Due to the small nature of the community, if any of these questions feel exposing there is no expectation that you have to answer, and I welcome your insight to reframe the question or its importance to note. Your feelings of safety are important to me, should you feel at any time during, after or in the days that follow the interview that you may need for your supports, please contact me as I will direct you to applicable community resources.

I will formally introduce myself to you and why this work is important to me. In brief, I am a queer, Latinx, migrant settler to Toronto, my ancestry arises from the Central American, country of El Salvador.

2. Backstory: Before I ask you to tell me about yourself to reflect upon your story of either your gender identity, sexual orientation or both and how they intersect with race, ethnicity or other cultural identities, is there anything you would like me to know about you, either before your life experiences navigating such intersections and/or LGBTQ spaces in Toronto? 
3. Story: I would like to hear about your story of your identity or identities formation, you may choose how to tell this story. You can tell this story in whatever way you feel best represents you and you are free to leave out anything you don't wish to share.

I look forward to listening to your story and the important markers personal to you during your identity formation and you can tell me about these experiences however you choose. You retain your autonomy in choosing what to include or leave out should there be anything you do not wish to share. However, should there be any disclosure of harm to another, harm to self, I have a duty to report. Any past or ongoing abuse that you have endured, I have a duty to report thus I ask you to keep this close to heart in the telling of your story.

Possible Guiding Questions:

- At what point in your life experiences did you become aware of your gender diverse identity and/or sexual orientation identity?

- Can you tell me about specific influence from your racial/ethnic/cultural background that informs your gender identity or sexual orientation?

- Can you tell me about an experience you had during your life (or a recent experience) when you felt you were on the sidelines looking in?

- Do you feel your voice is represented or your voice is heard in LGBTQ safe spaces?

- $\quad$ Do you feel value in reclaiming space? If so, what does that look like to you?

I am interested in hearing about your experiences in your cultural community and toward your location as a LGTBQ community member Possible Guiding Questions:

- Has the way your story about your identity formation shifted as you have aged? If so, what is important to your identity now, if not these things? 
- Can you tell me about an empowering experience that has promoted self-acceptance of your identity?

- What other experiences have helped you in your journey through self-acceptance?

- $\quad$ Can you tell me about some of the success and challenges in forming your current identity expression?

- At present, do you feel a sense of belonging with your racialized community, how has that shifted from when you came out?

- Since coming out, do you feel a strong sense of attachment to the LGBTQ community in the city?

- What recommendations would you suggest as urgent to the Latinx and the LGBTQ community in Toronto? Does social work have a role in this work? And how does that look like for you? 
Appendix F-Counselling Services for Participants

\section{Resources for Supports}

\section{COUNSELLING}

\section{Spirit People of the First Nations}

- For First Nations, Metis, and Inuit people who self-identify as 2-spirited and/or LGBTQ

- Not a lot of info on website

- Phone: 416-944-9300 ext. 224

- Address: 145 Front St E, Suite 105 (Front/Sherbourne)

\section{AIDS Committee of Toronto (ACT) Drop-In Counselling}

- For people living with or affected by HIV/AIDS as well as gay/bi/queer men and men who have sex with men

- First come, first serve basis Monday-Friday; call ahead for the drop-in hours for the day

- Able to call and book an appointment in advance

- Phone: 416-340-2437

- Address: 543 Yonge St, $4^{\text {th }}$ floor (Yonge/Wellesley)

\section{Canadian Centre for Victims of Torture}

- Call for more information

- Phone: 416-363-1066

\section{Centre for Interpersonal Relationships}

- Accessible low fee psychological treatment and assessment services to both Ottawa and Toronto communities

- Call for more information

- Phone: 1-855-779-2347

\section{David Kelley LGBTQ and HIV/AIDS Counselling Services}

- Free and sliding scale $(\$ 5+)$

- Medium-term individual and couples counselling; unlimited for those living with HIV/AIDS

- Phone: 416-595-9618

- Address: 202-128A Sterling Rd (Dundas St W/Lansdowne)

\section{Family Service Toronto Walk-In Counselling}

- Free walk-in counselling Wednesdays 3:30pm-7:30pm (last registration at $6: 15 \mathrm{pm})$, on a first come - first serve basis, with priority to first time clients 
- No identification required

- Phone: 416-595-9230 ext. 0

- Address: 355 Church St (Church/Gerrard)

\section{Parkdale Queen West Community Health Centre}

- Individual and group counselling

- Individual counselling: appointments available Monday-Friday 9:30am-5pm, some evening appointments available until 7:30pm

- Group counselling: times vary, check https://pqwchc.org/calendar/

- Phone: 416-703-8482 ext. 2106

- Address: 168 Bathurst St (Queen/Bathurst)

\section{Sherbourne Health Walk-In Counselling}

- Free walk-in counselling Tuesdays $12 \mathrm{pm}$, on a first come - first serve basis

- No health card, referral or appointment required

- Services are for those who are not receiving mental health counselling at Sherbourne or elsewhere

- Phone: 416-324-4109

- Address: 333 Sherbourne St (Sherbourne/Gerrard)

The 519

- Free drop-in counselling on Sundays, 11 am-2pm, March 24 and 31

- Free short-term counselling to individuals and couples - waitlist is closed until further notice (last updated Feb 21, 2019)

- Email: info@the519.org

- Phone: 416-392-6874

- Address: 519 Church St (Church/Wellesley)

\section{Umbrella Mental Health Network}

- Fee for service agency

- Email: info@umhn.ca

- Phone: 647-687-6543

- Address: 691 Bloor St W, Suite 202 (Bloor/Bathurst)

\section{WoodGreen Community Walk-In Counselling}

- Free walk-in counselling Tuesdays and Wednesdays 4:30pm-8:30pm (registration opens at 4:15pm and closes at 6:45pm)

- No health card, referral or appointment required

- Phone: 416-572-3575

- Address: 815 Danforth Ave, Suite 100 (Danforth/Jones) 


\section{References:}

Almario, M., Riggle, E. D., \& Rostosky, S. S. (2012). Positive themes in LGBT self-identities in select Spanish-speaking countries. PsycEXTRA Dataset.

Anzaldúa, G. (1987). Borderlands/The New Mestiza: La Frontera. San Francisco: Aunt Lute Books.

Bailey, M. M. (2014). Engendering space: Ballroom culture and the spatial practice of possibility in Detroit. Gender, Place \& Culture, 21(4), 489-507.

Bernal, D. D. (2002). Critical Race Theory, Latino Critical Theory, and Critical Raced-Gendered Epistemologies: Recognizing Students of Color as Holders and Creators of Knowledge. Qualitative Inquiry, 8(1), 105-126.

BOARD, E. (2019, Jul 12). Treatment of migrant kids shames USA: At a detention center, kids have gone hungry and without beds. they've seen outbreaks of scabies, shingles and chickenpox. for those watching, this is what a national disgrace looks like. Montgomery Advertiser Retrieved from http://ezproxy.lib.ryerson.ca/login?url=https://search-proquest com.ezproxy.lib.ryerson.ca/docview/2256010106?accountid=13631

Cahuas, M. C. (2018). Burned, Broke, and Brilliant: Latinx Community Workers' Experiences Across the Greater Toronto Area's Non-Profit Sector. Antipode, 51: 66-86.

Calafell, B. M. (2013). (I)dentities: Considering accountability, reflexivity, and intersectionality in the I and the we. Liminalities: A Journal of Performance Studies, 9(2), 6-13.

Cam, L. [LGBTCam]. 2019, January 07. Sara Ahmed: Queer Use [Video file]. Retrieved from https://www.youtube.com/watch?v=upkkoFVYfUE\&t=749s

Chamberlain, E. (2018). Beyond the Domestic Sphere: Desire, Intimacy, and Other Feelings in Collections of Queer Testimonios. Pacific Coast Philology, 53(2), 255-271. 
Chilisa, B. (2012). Decolonizing the interview method. Research methods in question. In Indigenous research methodologies (pp. 73-96). Los Angeles: SAGE.

Courtright, N. C. (2016, June 24). La cronología del movimiento LGTBQ en San Salvador. Retrieved from http://revistafactum.com/la-cronologia-del-movimiento-lgtb-salvador/

Crenshaw, K. (1991). Mapping the Margins: Intersectionality, Identity Politics, and Violence against Women of Color. Stanford Law Review,43(6), 1241. doi:10.2307/1229039

Daftary, A. H. (2018). Critical race theory: An effective framework for social work research. Journal of Ethnic \& Cultural Diversity in Social Work, 1-16.

de Vries, K. M. (2015). Transgender people of color at the center: Conceptualizing a new intersectional model. Ethnicities, 15(1), 3-27.

Doetsch-Kidder, S., \& Bracamonte, R. (2011). "my story is really not mine": An interview with Latina trans activist Ruby Bracamonte. Feminist Studies, 37(2), 441-467.

Dueñas, N. Y., Adames, H. Y., Perez-Chavez, J. G., Salas, S. P., Chavez-Dueñas, N. Y., Adames, H. Y., Salas, S. P. (2019). Healing ethno-racial trauma in latinx immigrant communities: Cultivating hope, resistance, and action. American Psychologist, 74(1), 49 62.

Estrada, G. S. (2003). An Aztec two-spirit cosmology: Re-sounding Nahuatl masculinities, elders, femininities, and youth. Frontiers: A Journal of Women Studies, 24(2/3), 10-14.

Fitzgerald, T. (2004). Powerful voices and powerful stories: Reflections on the challenges and dynamics of intercultural research. Journal of Intercultural Studies, 25 (3), 233-245.

Gamarel, K. E., Walker, J. J., Rivera, L., \& Golub, S. A. (2014). Identity Safety and Relational Health in Youth Spaces: A Needs Assessment with LGBTQ Youth of Color. Journal of LGBT Youth, 11(3), 289-315. doi:10.1080/19361653.2013.879464 
Garcia, C. (2017). In defense of Latinx [special section]. Composition Studies, 45(2), 210.

Giwa, S., \& Greensmith, C. (2012). Race relations and racism in the LGBTQ community of Toronto: Perceptions of gay and queer social service providers of color. Journal of Homosexuality, 59(2), 149-185.

Greensmith, C. (2015). The management of indigenous difference in Toronto's queer service sector. Settler Colonial Studies, 6(3), 252-264.

Greensmith, C. (2018). (Unsettling) White Queer Complicities: Toward a Practice of Decolonization in Queer Organizations. Intersectionalities: A Global Journal of 2018 Social Work Analysis, Research, Polity, and Practice, 6(1)

Harrison, B. F., \& Michelson, M. R. (2017). Listen, we need to talk: How to change attitudes about LGBT rights. Oxford University Press

Hudson, K. D., \& Mehrotra, G. R. (2015). Locating queer-mixed experiences: Narratives of geography and migration. Qualitative Social Work, 14(5), 651-669.

Human Rights Campaign. (n.d.). Violence Against the Transgender Community in 2018. Retrieved October 21, 2018, from https://www.hrc.org/resources/violence-against-the transgender-community-in-2018

Hicks, S., \& Jeyasingham, D. (2016). Social work, queer theory and after: A genealogy of sexuality theory in neo-liberal times. British Journal of Social Work, 46(8), 2357-2373.

Jiménez, P. K. (2008). Latina Landscape: Queer Toronto. Canadian Journal of Environmental Education, 13(2)

Kline, N., \& Cuevas, C. (2018). Resisting Identity Erasure after Pulse: Intersectional LGBTQ Latinx Activism in Orlando, FL. Chiricú Journal: Latina/o Literatures, Arts, and Cultures,2(2), 68-71. 
Knapp, C. E. (2013). Two-eyed seeing as a way of knowing. Green Teacher, (99), 31.

Krumer-Nevo, M. (2002). The Arena of Othering: A Life-Story Study with Women Living in Poverty and Social Marginality. Qualitative Social Work, 1(3), 303-318.

Ladson-Billings, G. (2003). Racialized discourses and ethnic epistemologies. In N. Denzin \& Y. Lincoln (Eds.). Handbook of qualitative research. California: Sage.

Logie, C. H., \& Rwigema, M. (2014). “The Normative Idea of Queer is a White Person”: Understanding Perceptions of White Privilege Among Lesbian, Bisexual, and Queer Women of Color in Toronto, Canada. Journal of Lesbian Studies, 18(2), 174-191.

Medecins Sans Frontieres. (2017). FORCED TO FLEE CENTRAL AMERICA'S NORTHERN TRIANGLE: A NEGLECTED HUMANITARIAN CRISIS (Rep.). Retrieved https://www.doctorswithoutborders.ca/sites/default/files/msf_forced-to-flee-central americas-northern-triangle_0.pdf

Milian, C. (2017). Extremely Latin, XOXO: Notes on LatinX. Cultural Dynamics, 29(3), 121 $-140$

de Onís, C, (K), M. (2017). What's in an "x"?: An exchange about the politics of “Latinx”.Chiricù Journal: Latina/o Literature, Art, and Culture, 1(2), 78-91.

Pastrana, A. (., Jr), Battle, J., \& Harris, A. (2017). An examination of Latinx LGBT populations across the united states: Intersections of race and sexuality. Palgrave Macmillan.

Peltier, C. (2018). An application of two-eyed seeing: Indigenous research methods with participatory action research. International Journal of Qualitative Methods, 17(1), 160940691881234.

Pérez, E. (2003). Queering the Borderlands: The Challenges of Excavating the Invisible and Unheard. Frontiers: A Journal of Women Studies, 24(2/3), 122-131. 
Quiñones Mayo, Y., \& Resnick, R. P. (1996). The impact of machismo on Hispanic women. Affilia, 11(3), 257-277.

Ramírez, H. N. (2006). Borderlands, Diasporas, and Transnational Crossings: Teaching LGBT Latina and Latino Histories. OAH Magazine of History, 20(2), 39-42.

Reyes Cruz, M. (2008). What If I Just Cite Graciela? Working Toward Decolonizing Knowledge Through a Critical Ethnography. Qualitative Inquiry, 14(4), 651-658.

Reyes, K. B., \& Curry Rodríguez, J. E. (2012). Testimonio: Origins, terms, and resources. Equity \& Excellence in Education, 45(3), 525-538.

Robinson, M. (2017). Two-spirit and bisexual people: Different umbrella, same rain. Journal of Bisexuality, 17(1), 7-29.

Sausa, L. A., Keatley, J., \& Operario, D. (2007). Perceived Risks and Benefits of Sex Work among Transgender Women of Color in San Francisco. Archives of Sexual Behavior,36(6), 768-777.

Smith, A. (2010). Queer theory and native studies: The heteronormativity of settler colonialism. GLQ: A Journal of Lesbian and Gay Studies, 16(1), 42-68

S, V. M., \& Sánchez, S. (2003). Memorias de la sangre, memorias de la tierra. pertenencia, identidad y memoria entre los indígenas del noroeste argentino, atacama y chile central durante el período colonial. Estudios Atacameños, (26), 45-59.

Truth and Reconciliation Commission of Canada. (2015). Truth and Reconciliation Commission of Canada: Calls to Action. Retrieved from http://nctr.ca/assets/reports/Calls_to_Action_English2.pdf 
Torrez, J. E., Gonzales, L., Del Hierro, V., Ramos, S., \& Cuevas, E. (2019). Comunidad de cuentistas: Making space for indigenous and latinx storytellers. English Journal, 108(3), 44-50.

Tuck, E., \& Yang, K, W. (2012). Decolonization is not a metaphor. Decolonization: Indigeneity, Education \& Society, 1, 1-40.

Whitfield, D. L., Walls, N. E., Langenderfer-Magruder, L., \& Clark, B. (2014). Queer Is the New Black? Not So Much: Racial Disparities in Anti-LGBTQ Discrimination. Journal of Gay \& Lesbian Social Services, 26(4), 426-440.

Wheeler, J., Anfinson, K., Valvert, D., \& Lungo, S. (2014). Is violence associated with increased risk behavior among MSM? evidence from a population-based survey conducted across nine cities in central america. Global Health Action, 7(1), 24814-12. 